\title{
REVIEW ARTICLE OPEN Harnessing nanomedicine to overcome the immunosuppressive tumor microenvironment
}

\author{
Bo Sun ${ }^{1}$, Hyesun Hyun ${ }^{2,3}$, Lian-tao $\mathrm{Li}^{4,5}$ and Andrew Z Wang ${ }^{2,3}$
}

\begin{abstract}
Cancer immunotherapy has received extensive attention due to its ability to activate the innate or adaptive immune systems of patients to combat tumors. Despite a few clinical successes, further endeavors are still needed to tackle unresolved issues, including limited response rates, development of resistance, and immune-related toxicities. Accumulating evidence has pinpointed the tumor microenvironment (TME) as one of the major obstacles in cancer immunotherapy due to its detrimental impacts on tumor-infiltrating immune cells. Nanomedicine has been battling with the TME in the past several decades, and the experience obtained could be exploited to improve current paradigms of immunotherapy. Here, we discuss the metabolic features of the TME and its influence on different types of immune cells. The recent progress in nanoenabled cancer immunotherapy has been summarized with a highlight on the modulation of immune cells, tumor stroma, cytokines and enzymes to reverse the immunosuppressive TME.
\end{abstract}

Keywords: cancer immunotherapy; tumor microenvironment; immunosuppression; immune cells; cytokines; enzymes; nanomedicine

Acta Pharmacologica Sinica (2020) 41:970-985; https://doi.org/10.1038/s41401-020-0424-4

\section{INTRODUCTION}

The tumor microenvironment (TME) is a complex ecosystem consisting of not only tumor cells but also vasculature, stroma, infiltrating immune cells, fibroblasts, and other noncellular tissues $[1,2]$. Tumor vasculature has striking differences from vessel networks in normal tissues. Leaky vasculature is malformed under elevated levels of vascular endothelial growth factor (VEGF), which is secreted by fast-growing tumor cells [3]. The disorganized patterns and abnormal diameters of tumor vessels result in nonuniform oxygen and nutrient supplies for cancer cells $[4,5]$. Hypoxia has been found in more than $50 \%$ of solid tumors because the oxygen supply from aberrant tumor vasculature cannot meet the need for rapid tumor development [6]. Furthermore, tumors adopt aerobic glycolysis as a main source of ATP to feed rapidly proliferating cells [7]. Acidic products from aerobic glycolysis, such as lactate, contribute to the lower $\mathrm{pH}$ in the extracellular matrix (ECM) of tumors than in normal tissues $[8,9]$. Hypoxia-inducible factor (HIF-1) can aggravate acidosis by upregulating glycolytic enzymes, glucose transporters and lactate production [10]. High interstitial fluid pressure (IFP) is another important physiological parameter of the TME. Compression from the increasing tumor mass, hyperpermeable vascular walls and the absence of functional lymphatic vessels contributes to elevated fluid pressure within tumors [11, 12]. Hypoxia, acidosis, and IFP fortify the TME against the entry of therapeutics and immune attack (Fig. 1) [13].

\section{THE INTERPLAY BETWEEN IMMUNE CELLS AND THE TME}

Growing evidence has underscored the significant roles of immune cells in different phases of tumor progression. Major immune cells in the TME include macrophages, dendritic cells (DCs), neutrophils, monocytes, myeloid-derived suppressor cells (MDSCs), natural killer (NK) cells, T cells, and B cells (Fig. 2) [14, 15]. The interplay between immune cells and other cellular and noncellular components in the TME largely determines disease progression and therapeutic outcomes [16]. In addition to the aforementioned cardinal features of the TME, altered tumor metabolism is detrimental to the activation of immune cells and subsequent differentiation and memory formation [17]. In addition to hypoxia, glucose depletion and lactate production, amino acid depletion and increased lipid metabolism also play critical roles in the inhibition of effector cells, induction of regulatory/suppressor cells and upregulation of programmed cell death-ligand-1 (PD-L1) in the TME [18, 19].

Similar to cancer cells, activated $\mathrm{T}$ lymphocytes upregulate aerobic glycolysis and glutamine metabolism to facilitate the proliferation and differentiation of effector T cells (T-effs) [20]. Tumor cells compete with T cells for nutrients in the TME due to their similar metabolic processes, resulting in compromised T-cell receptor (TCR) signaling and dampened production of cytokines such as interferon- $\gamma$ (IFN- $\gamma)$, interleukin-2 (IL-2), and tumor necrosis factor- $a$ (TNF- $a$ ) [21-23]. Furthermore, exhausted T cells are also characterized by high expression of several immune checkpoint

\footnotetext{
${ }^{1}$ Department of Pharmacology and Toxicology, College of Pharmacy, University of Arizona, Tucson, AZ 85721, USA; ${ }^{2}$ Laboratory of Nano and Translational Medicine, Carolina

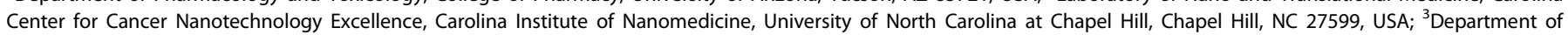

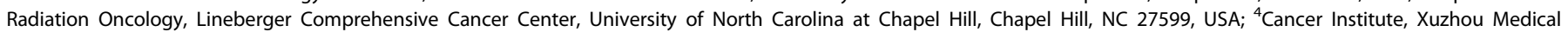
University, Xuzhou 221004, China and ${ }^{5}$ Department of Radiation Oncology, Affiliated Hospital of Xuzhou Medical University, Xuzhou 221004, China Correspondence: Andrew Z Wang (zawang@med.unc.edu)
} 

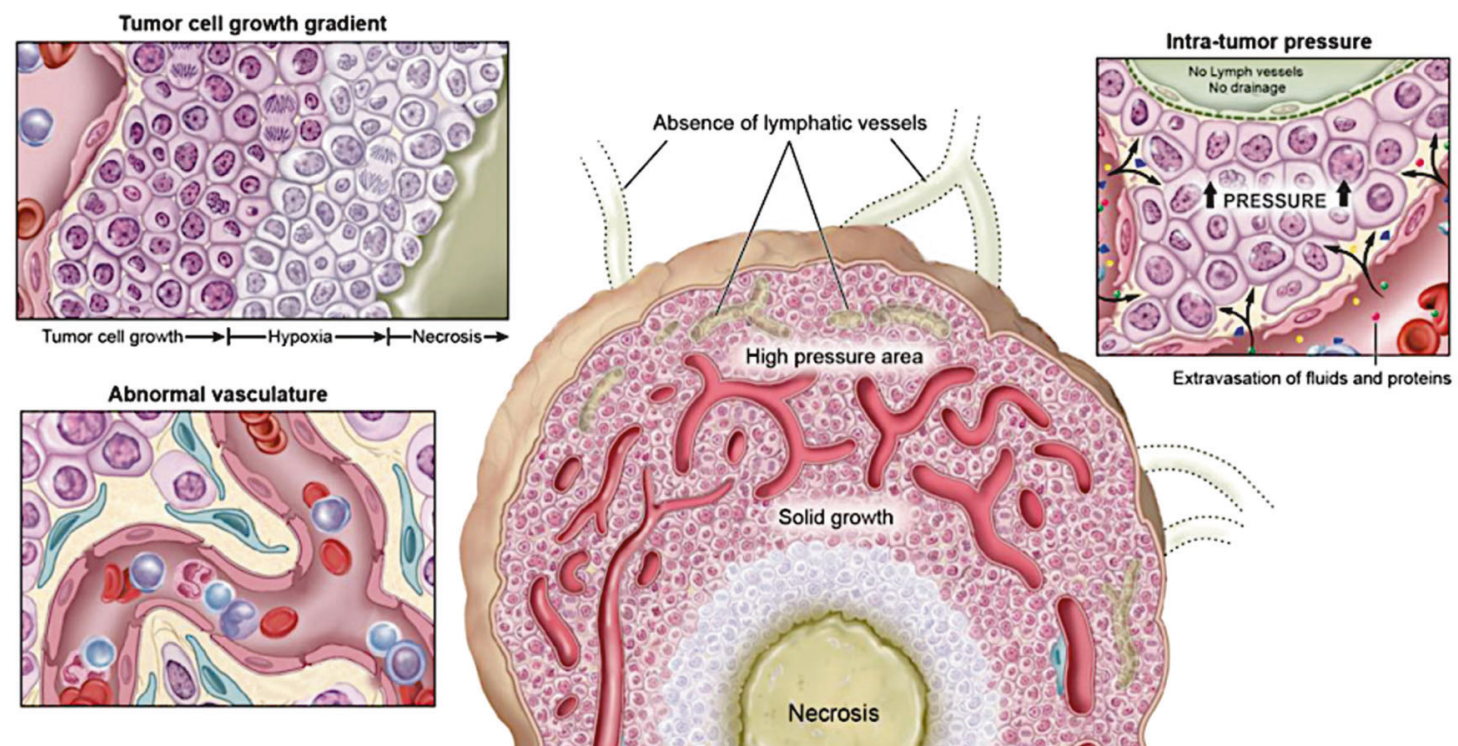

Extravasation of fluids and proteins

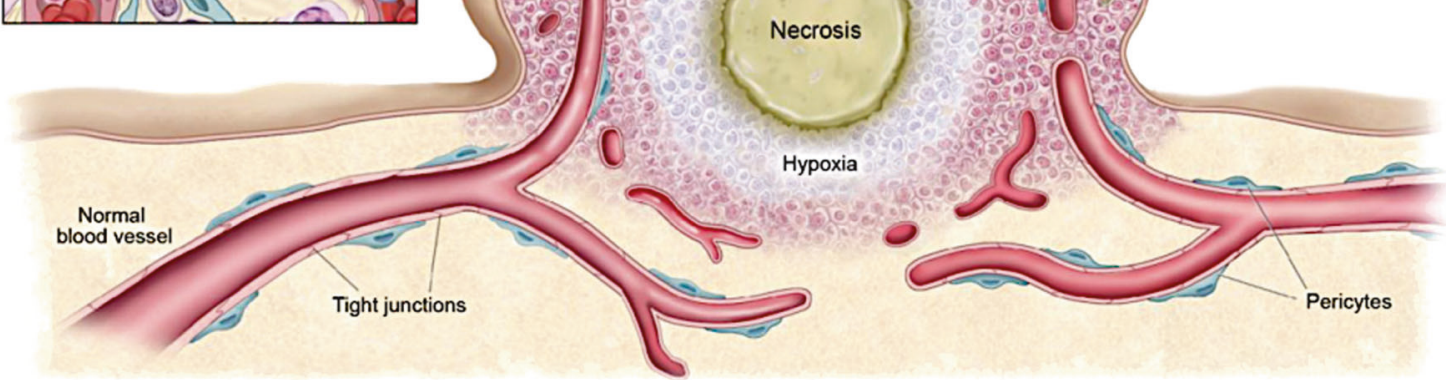

Fig. 1 Physiological characteristics of tumor tissue and vasculatures. Adapted from REF [13] with permission by Theranostics under Creative Commons Attribution (CC BY-NC) License.

receptors, such as PD-1, cytotoxic T-lymphocyte-associated protein 4 (CTLA-4), T-cell immunoglobulin and mucin-domain containing-3 (TIM-3) and lymphocyte activation gene-3 (LAG-3), which lead to impaired T-cell functions [24, 25]. The immunosuppressive TME also affects the functions of NK cells, another major player in antitumor immunity whose tumoricidal effect is manipulated by a balance between inhibitory and activating signaling after priming by DCs, macrophages, and/or interleukins [26-28]. Glucose depletion represses the cytotoxic activity and cytokine production of NK cells in the TME $[29,30]$. Accumulated metabolites in the TME, such as adenosine and lactate, also suppress the functions and survival of NK and T cells [31, 32]. The limited availability of arginine, leucine, and glutamine has a direct impact on mammalian target of rapamycin complex 1 and c-Myc signaling, which control the differentiation and functions of NK and $T$ cells $[33,34]$. In addition, the proliferation and cytokine production of NK cells can be inhibited by increased catabolites of amino acids that are mediated by upregulated enzymes, such as indoleamine 2,3-dioxygenase (IDO), arginase, and inducible nitric oxide synthase (iNOS) [35-38].

Among these tumor-infiltrated immune cells, tumor-associated macrophages (TAMs) are probably the largest population in the TME $[2,39]$. TAMs not only coexist but also coevolve with tumor cells. In response to tumor progression, M2-like TAMs result from interactions between tumor cells and M1-like TAMs that are predominant in very early oncogenesis $[40,41]$. Under the influence of neighboring cancer cells, M2-like TAMs foster malignancy by releasing cytokines, such as IL-6, TNF-a and C-C chemokine ligands, promoting aerobic glycolysis and hypoxia $[42,43]$. M2-polarized TAMs also dysregulate immune responses by promoting PD-L1 expression, remodeling the ECM to trap infiltrating $\mathrm{T}$ cells, and producing phagocytosis-inhibiting proteins and enzymes that favor metabolite accumulation in the TME [44-46].
Hypoxia has complex roles in the immunosuppressive TME. Hypoxia induces tumor cells to secrete immunosuppressive molecules, such as transforming growth factor- $\beta$, VEGF, IL-10, CC-chemokine ligands, galectins, and COX-2, contributing to the generation and accumulation of M2-polarized TAMs, regulatory T cells and MDSCs, which suppress DCs and T cells in the TME and negatively regulate tumor antigen presentation [47]. Hypoxia also has a direct impact on antitumor effector cells. Recent studies have shown that hypoxia does not compromise the cytolytic capacities of cytotoxic T lymphocytes (CTLs) but restricts the number of CTLs in the TME to control tumor growth [48]. Interestingly, a few studies suggested a positive role of hypoxia in CTLs. Hypoxia stimulates the upregulation of 4-1BB on the surface of activated $T$ cells, which could potentially benefit anti-4-1BB agonist therapy [49,50]. The function of NK cells is partially inhibited by hypoxia. NK cells fail to upregulate surface expression of several activating receptors under hypoxia, but antibodydependent cellular cytotoxicity is not affected [51, 52]. The influence of hypoxia on T and NK cells is still unclear and warrants further study.

In recent decades, many therapeutic strategies have been developed to target different aspects of the TME. As one promising strategy, nanomedicine represents a versatile platform that exploits nanoparticles (NPs), which are fine-tuned nanoscale materials for drug delivery and diagnosis [53]. The physicochemical properties of NPs, such as size, shape, and surface charge, can be tailored to perform controlled release of payloads, passively accumulate at tumors by enhanced permeability and retention effects, or specifically target tumors [54]. NPs incorporated with physical and biological technologies have already been utilized in the delivery of vaccine adjuvants, cytokines, and immune checkpoint blockades (ICBs) to modulate the TME (Table 1), with the aim of improving the outcomes of current radiotherapy, chemotherapy, and immunotherapy [55]. Herein, 


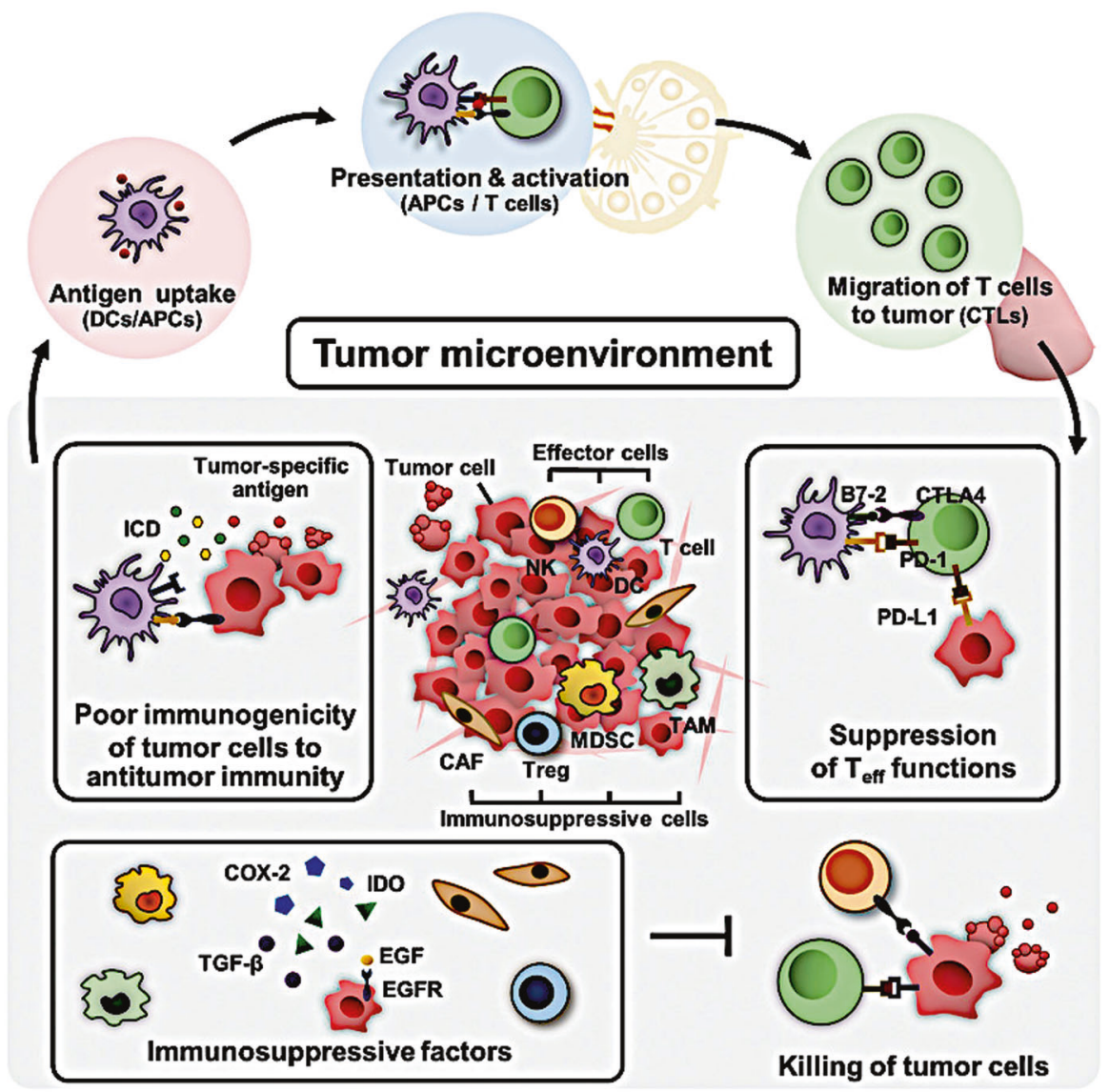

Fig. 2 Immune cells in the immunosuppressive TME. DCs/APCs: dendritic cells/antigen-presenting cells, CTLs: cytotoxic T lymphocytes, ICD: immunogenic cell death, NK: natural killer cells, CAF: cancer-associated fibroblasts, Treg: regulatory T-cells, MDSC: myeloid-derived suppressor cells, TAM: tumor-associated macrophages, $\mathrm{T}_{\text {eff }}$ : effector T-cells, COX-2: cyclooxygenase-2, IDO: indoleamine 2,3-dioxygenase, TGF- $\beta$ : transforming growth factor- $\beta$, EGFR: epithelial growth factor receptor. Adapted from REF [167] with permission by WILEY-VCH.

we discuss the immunometabolism of major immune cells in the TME and summarize the recent progress in nanomedicine that reprograms these cells in an immunosuppressive context, which represents new strategies for the development of nextgeneration immunotherapies.

\section{MODULATION OF IMMUNE CELLS IN THE TME}

\section{Modulation of T-effs}

Metabolic reprogramming in $\mathrm{T}$ cells is triggered by antigen recognition by the TCR in the presence of costimulatory factors. Aerobic glycolysis is adopted to provide energy and nutrients more efficiently during T-cell activation than oxidative phosphorylation (OXPHOS) [21]. PI3K/Akt/mTOR and c-Myc are two key signaling pathways that elevate the expression of glucose transporter-1, which facilitates glycolysis in T-effs [56]. However, these two pathways could be compromised by reduced glutamine and leucine metabolism in the TME, resulting in hampered T-cell activation [57]. Lipid metabolism also plays an essential role in the functions of T-effs. An increased level of cholesterol was found in activated $\mathrm{CD}^{+} \mathrm{T}$ cells, which promotes TCR clustering and signaling [58]. Enhanced fatty acid catabolism would be helpful for maintaining the function of $\mathrm{CD}^{+}{ }^{+}$cells in the malnourished TME [59]. For example, acetyl-CoA acetyltransferase-1 (ACAT-1) is a cholesterol esterification enzyme expressed in $\mathrm{CD}^{+} \mathrm{T}$ cells that downregulates T-cell activation by reducing free cholesterol levels [58]. In an effort to potentiate $\mathrm{CD}^{+}{ }^{+}$T cells, avasimibe, an ACAT-1 inhibitor, was combined with nanoliposomes containing paclitaxel and the immunoadjuvant a-GalCer for chemoimmunotherapy of a melanoma model [60]. Avasimibe strengthened the cytotoxicity of $\mathrm{CD}^{+}{ }^{+}$cells by inhibiting ACAT- 1 and increasing free cholesterol in the plasma membrane. This combined therapy significantly suppressed tumor growth and prolonged the survival of mice with melanoma compared with those treated with any single therapy.

Immune checkpoint signaling has significant impacts on the glucose metabolism of tumor cells and $T$ cells. Antibodies or antibody-conjugated NPs that bind PD-1/PD-L1, 4-1BB, or CTLA-4 can restore glucose levels in the TME by regulating the Akt/mTOR or liver kinase B1/AMP-activated protein kinase/acetyl-CoA carboxylase signaling pathway, allowing T-cell glycolysis and cytokine production $[22,61,62]$. Galstyan et al. developed poly ( $\beta$ - $L$-malic acid) nanoconjugates to facilitate delivery of checkpoint inhibitory antibodies to brain glioma across the blood brain barrier (BBB) [63]. Anti-CTLA-4 or anti-PD-1 were covalently conjugated to the polymer backbone, and BBB crossing was achieved with transferrin receptor antibodies. An increase in $\mathrm{CD}^{+} \mathrm{T}$ cells was observed in the interstitium of intracranial GL261 glioblastoma treated with a combination of two checkpoint inhibitory antibodynanoscale immunoconjugates (NICs). The survival of tumorbearing mice was markedly prolonged when treated with the NIC combination in comparison with free antibodies or single antibody NIC. This study underscored the potential of polymerbased trans-BBB delivery to improve the local immune response to brain tumors.

$\mathrm{CD}^{+} \mathrm{T}$ cells can differentiate into a variety of subtypes and thus coordinate a wide range of immune responses in autoimmune diseases, inflammatory diseases, and cancers [64, 65]. Generally, $\mathrm{CD}^{+}{ }^{+}$T cells can be divided into two subsets, $\mathrm{T}$ helper 1 


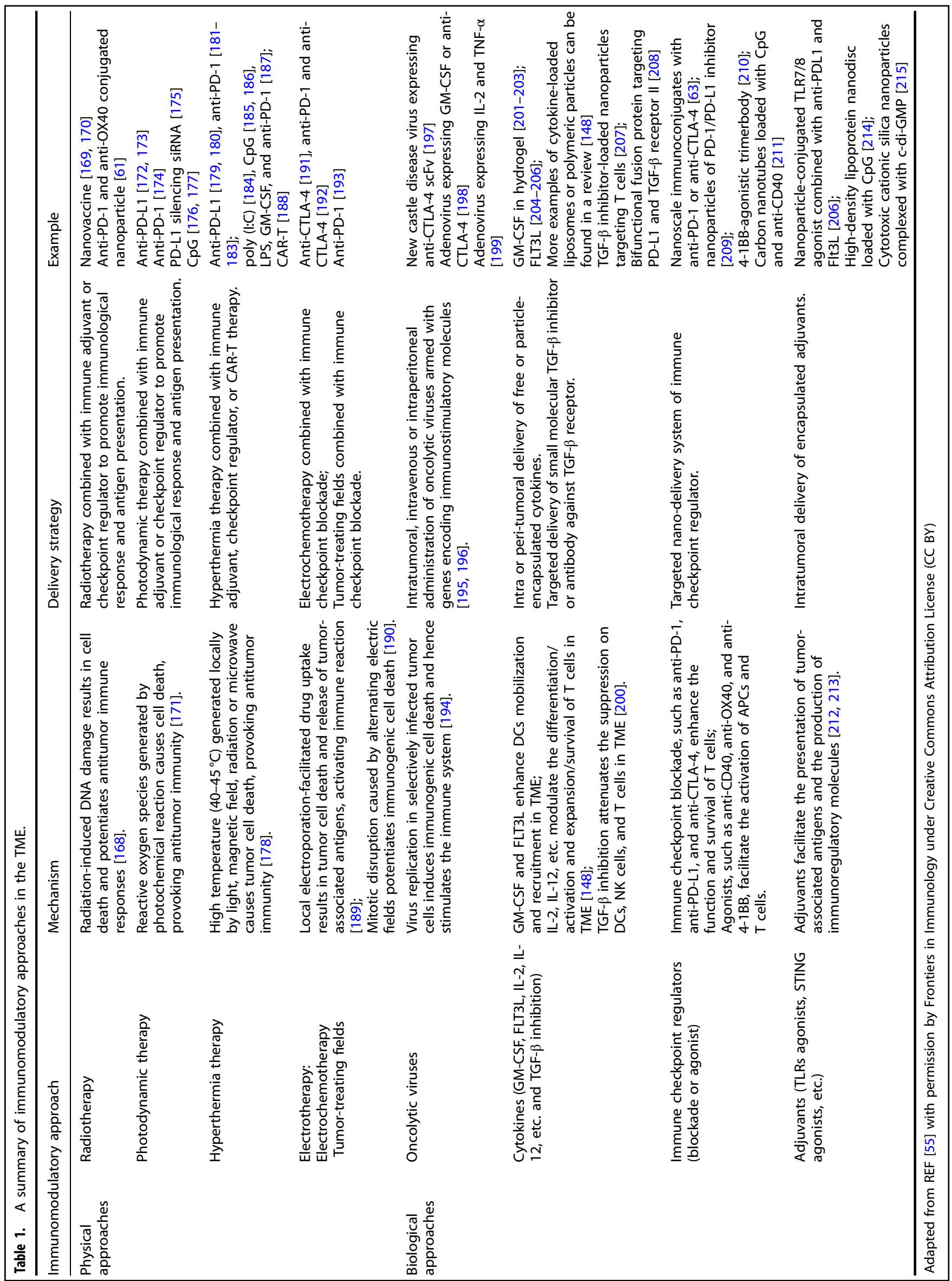


a

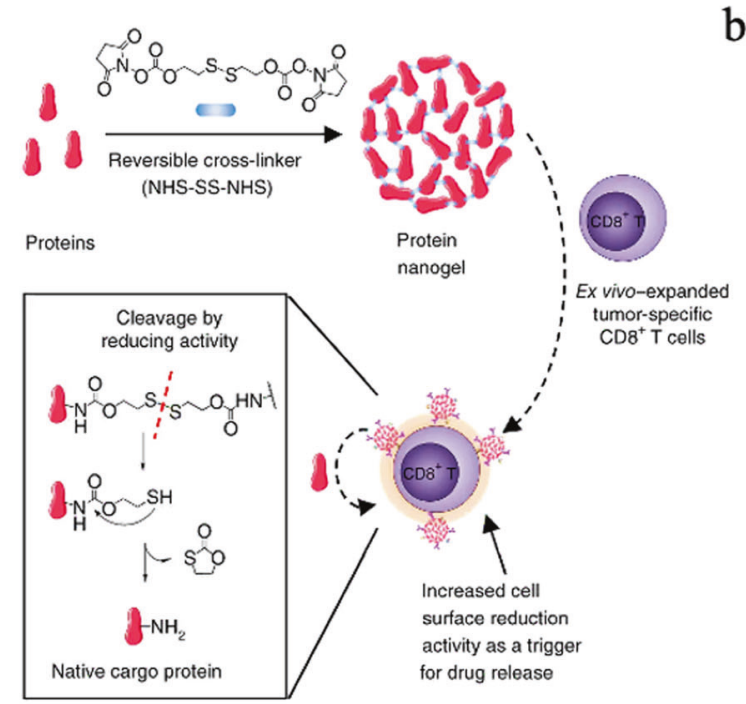

C

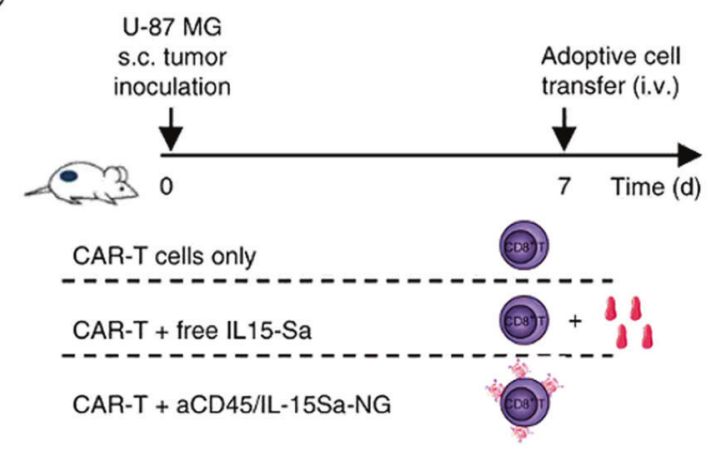

$\mathrm{e}$

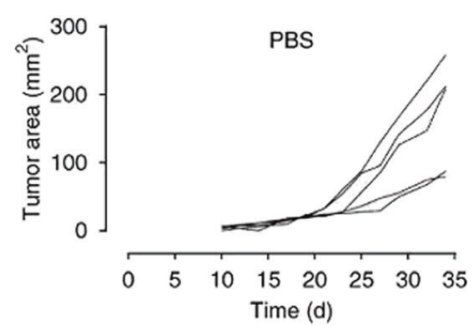

b

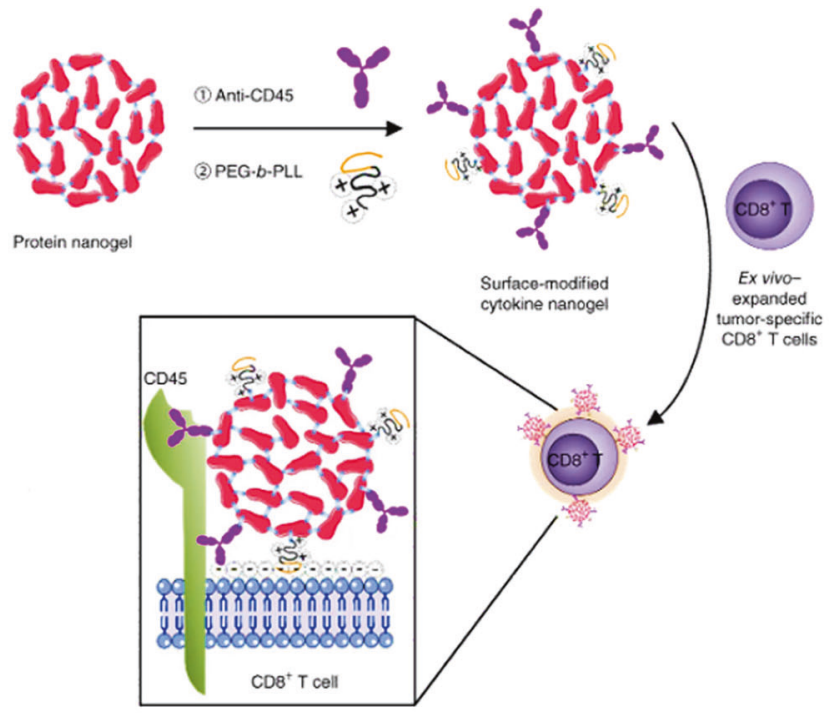

$\mathrm{d}$
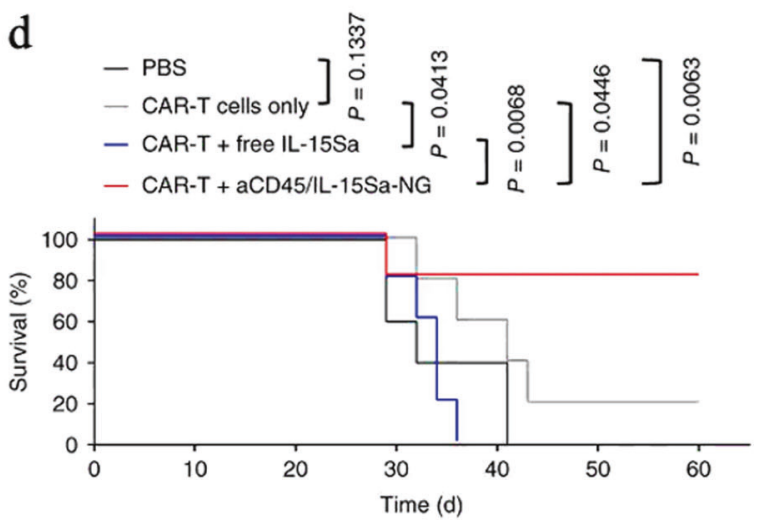

CAR-T +

free IL-15Sa

CAR-T +

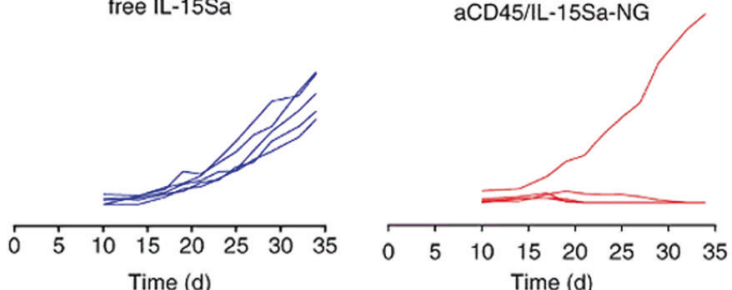

Fig. 3 a Scheme for protein nanogel synthesis and for release of protein in response to reducing activity in the local microenvironment. b Scheme for surface modification of cytokine-nanogels to facilitate efficient and stable anchoring on T-cell surface. c Experimental scheme. Luciferase-expressing U-87 MG human glioblastoma cells $\left(1.0 \times 10^{6}\right)$ were subcutaneously injected into NSG mice $(n=5$ mice/group). Mice received i.v. adoptive transfer of human T cells $\left(2.6 \times 10^{6}\right.$ total cells, $38 \%$ transduced with EGFR-targeting CAR $\left(1.0 \times 10^{6}\right.$ CAR-T cells)) on day 7 . Mice were treated with sham saline injections, CAR-T cells alone, CAR-T cells followed by $13.8 \mu \mathrm{g}$ of free IL-15Sa, or CAR-T cells coupled with aCD45/IL-15Sa-nanogels $(13.8 \mu \mathrm{g})$. d Survival curves of treatment groups. e Individual tumor growth curves. Statistical analyses were performed by using two-way ANOVA test for tumor growth data and log-rank test for survival curves. Data represent the mean \pm SEM. All data are one representative of at least two independent experiments. Adapted from REF [71] with permission by Springer Nature.

(Th1), and T helper 2 (Th2), which elicit antitumor effects and tumor-promoting effects, respectively. Emerging subsets, such as immunosuppressive regulatory $T$ cells, follicular helper $T$ cells, and Th9, Th17 and Th22 cells, have also been classified [66-68]. Outstanding examples of nanomedicine specifically modulating $\mathrm{CD}^{+}{ }^{+}$cells have not been adequately reported, probably due to the diversity of the $\mathrm{CD}^{+}$population and their plasticity in response to different immune microenvironments [69].

Targeted T-cell therapies have demonstrated great promise in the treatment of blood cancer. In 2017-2018, two T-cell therapies, Yescarta ${ }^{\mathrm{TM}}$, and Kymriah ${ }^{\mathrm{TM}}$, were approved by the FDA for adult patients suffering from relapsed or refractory lymphoma and leukemia [70]. However, applying the same paradigm in solid malignancies may not be an easy task. Malformed vasculature and a nutrient-depleted TME represent one of the major hurdles between antigen-specific $T$ cells and tumors. To maintain the viability of tumor-specific T cells, supportive NPs filled with interleukin-15 super-agonist complex (IL-15Sa) were attached to the T-cell surface via anti-CD45 antibodies (Fig. 3) [71]. IL-15Sa release was initiated upon T-cell activation. Tumor growth was significantly suppressed after multiple administrations of T cells equipped with cytokine backpacks without inducing dose-limited toxicity compared with that of mice that received equivalent doses of T-cell transfer alone or T-cell transfer plus free cytokines. 
In another effort to create a stimulatory tumor milieu for subsequent T-cell infusion, a PI3K inhibitor (PI-3065) and invariant natural killer T-cell (iNKT) activator (7DW8-5) were codelivered in liposomes decorated with tumor-targeting iRGD peptides [72]. Immune suppressing cells were reduced more than fourfold in the 4T1 tumor milieu after treatment with multiple doses of dual-drug liposomes in contrast to those treated with empty vehicles. This TME priming strategy augmented the accumulation of T-effs, such as $\mathrm{CDB}^{+} \mathrm{T}$ cells and $\mathrm{iNKT}$, in tumors and thus boosted the therapeutic effect of subsequent T-cell therapy.

\section{Modulation of regulatory $T$ cells (T-regs)}

In contrast to T-effs, T-regs play an essential role in the immune escape of tumors, and the TME favors T-reg recruitment and differentiation [47, 73]. A marked increase in T-regs in the TME has been recognized as a hallmark of many solid malignancies. Under hypoxia, HIF-1a in T-regs enhances the migration and suppressive effects of T-regs in the TME [74]. The proliferation and function of T-regs are supported by their flexibility in shifting metabolic processes to survive in a glucose-restricted but lactate-abundant setting in comparison with rigid T-effs. Several studies have shown that T-regs have a stronger ability to compete for glucose and execute glycolysis than T-effs, which leads to T-cell exhaustion in cooperation with tumor cells $[20,75,76]$. In addition to glucose competition, T-regs take up and utilize accumulated fatty acids in the TME via fatty acid oxidation (FAO) to fuel and modulate their expansion and inhibitory activities [77, 78]. Moreover, T-regs suppress activated $\mathrm{T}$ cells and APCs by releasing inhibitory molecules, including IL- $2,4,6$, TGF- $\beta$, granzymes, and perforin $[79,80]$.

Recent studies have highlighted the crucial roles of glucocorticoid-induced tumor necrosis factor receptor-related protein (GITR, CD357) in activated T cells and T-regs [81]. Agonistic antibodies targeting GITR exert evident therapeutic effects by depleting T-regs and reinvigorating $\mathrm{CD} 8^{+} \mathrm{T}$ cells by reducing PD-1 and LAG-3 expression [82]. However, anti-GITR monotherapy may be inadequate to achieve significantly improved clinical responses [81]. Anti-GITR therapy was combined with anti-PD1 therapy to attenuate the immunosuppression of T-regs induced by radiation therapy in an anti-PD1-resistant preclinical tumor model, yielding improved survival and tumor eradication [83]. In addition to agonistic monoclonal antibodies, the small molecular drug imatinib, an inhibitor of T-regs and IDO pathway in tumor cells $[84,85]$, was combined with photodynamic/thermal therapy for photoimmunotherapy in a preclinical model of melanoma [86]. Imatinib and the near-infrared (NIR) photosensitizer IR-780 were coencapsulated in PLGA hybrid nanoparticles (hNPs) with hybrid surface layers for $\mathrm{pH}$-triggered release of payloads in the acidic TME. Tumor ablation was observed in the mice that were treated with hNPs plus NIR irradiation, and $80 \%$ of them survived until the end of the efficacy study (60 days), while mice that were treated with PBS, free imatinib or free IR-780 hardly lived for 50 days. Immunohistochemical evaluation and flow cytometry results demonstrated an increased population of $\mathrm{CD}^{+}$and $\mathrm{CD}^{+}{ }^{\mathrm{T}}$ cells and a reduction in T-regs in the TME of mice treated with hNPs plus photoinduced therapy, which supports the hypothesis that imatinib-loaded hNPs inhibit the suppressive effects of T-regs and hence protect tumor antigen presentation and cytotoxic T cells.

\section{Modulation of MDSCs}

MDSCs are a group of heterogeneous immature myeloid cells that are generated in bone marrow and migrate to primary and metastatic tumors in response to cytokines or other immune mediators secreted by tumor cells [87]. Generally, two subsets of MDSCs have been identified in both humans and mice: polymorphonuclear MDSCs and monocytic MDSCs. Both subsets exert more potent nonspecific suppressive activities when recruited to tumor sites than their counterparts in peripheral lymphoid tissues, but the latter is believed to have a predominant role in T-cell suppression [88]. In the acidic and hypoxic TME, tumor-infiltrating MDSCs are driven to adopt FAO and OXPHOS as their main metabolic pathways $[88,89]$. MDSCs also upregulate their expression of iNOS and arginase 1 and rapidly differentiate into TAMs [38]. MDSCs obstruct T-cell functions by depleting key nutrients such as arginine, cysteine and tryptophan (Trp) [88]. Furthermore, MDSCs have been linked to the induction of T-regs in the TME $[90,91]$.

Compelling evidence has demonstrated that, similar to TAMs, MDSCs also have M1 and M2 phenotypes [92, 93]. M1-like MDSCs are characterized as tumor-inhibiting cells by the production of TNF-a, IL-12, and nitric oxide, whereas M2-type MDSCs thwart the tumoricidal effect of T lymphocytes or NK cells by secreting TGF- $\beta$, IL-10 and arginase [94]. The repolarization of MDSCs may represent a new strategy to optimize current cancer immunotherapy. Several studies have shown that Toll-like receptor (TLR) signaling ligands hinder the immunosuppressive activity of MDSCs [95-97]. A study by Zhang et al. showed that cationic polymers, such as cationic dextran and polyethyleneimine, directly repolarize MDSCs and TAMs to the M1 phenotype via TLR4 signaling and promote the expression of Th1-inducing cytokines $[98,99]$. Another study reported that synthetic highdensity lipoprotein-based NPs have high affinity to scavenger receptor type $\mathrm{B}-1$, which is expressed on MDSCs, and thus attenuate the immunosuppressive function of MDSCs [100]. However, further scrutinization may be needed to obtain more convincing corroboration for the interactions between these macromolecules and immune cells.

Small molecular drugs also have potential to keep tumorinduced MDSCs at bay. Selective inhibition of MDSCs has been added to the portfolio of several well-known anticancer drugs, such as gemcitabine (GEM) [101], curcumin [102], and docetaxel [92], yet the mechanisms still need further investigation. Phuengkham et al. developed a hydrogel depot (iCD) containing tumor lysate, poly $(I: C)$ in nanogel and GEM to revert the immunosuppressive TME and prevent postsurgical tumor recurrence and metastasis (Fig. 4) [103]. The peritumorally implanted scaffold prevented local recurrence of advanced 4T1 breast tumors and possible metastasis to the lungs, which were attributed to the synergy between MDSC-depleting GEM and vaccine-induced antitumor immunity. Sunitinib is an FDAapproved tyrosine kinase receptor (TKR) inhibitor for cancer chemotherapy. It has been proven to be a potent immunomodulator because it also targets TKRs expressed on MDSCs and thus depletes MDSCs in the circulation, spleen, and tumor [104-106]. Sunitinib could be encapsulated in polymeric micelles and utilized as an auxiliary treatment for cancer vaccines against advanced melanoma [107]. Antitumor immunity was strengthened by a reduced number of MDSCs and T-regs and increased influx of cytotoxic T cells and Th1 cytokine profiles when tumors were pretreated with micellar sunitinib. The same research team published a similar study with NPs loaded with CDDO-Me, a synthetic oleanane triterpenoid with anticancer properties, which augmented the vaccine-induced T-cell response against melanoma by blocking the function of MDSCs [108].

Modulation of TAMs

TAMs constitute a significant portion of cell populations in the TME and serve as major tumor-promoting immune cells, in addition to T-regs and MDSCs [109]. Macrophages with the M1 phenotype have cytotoxicity and upregulate the production of proinflammatory cytokines. However, M2-like TAMs secrete immunosuppressive cytokines, including IL-10 and TGF- $\beta$, which contribute to tumor progression and resistance to chemotherapies in part by inhibiting MHC-mediated antigen presentation and stimulating apoptosis of lymphocytes (Fig. 5) [110, 111]. Moreover, 

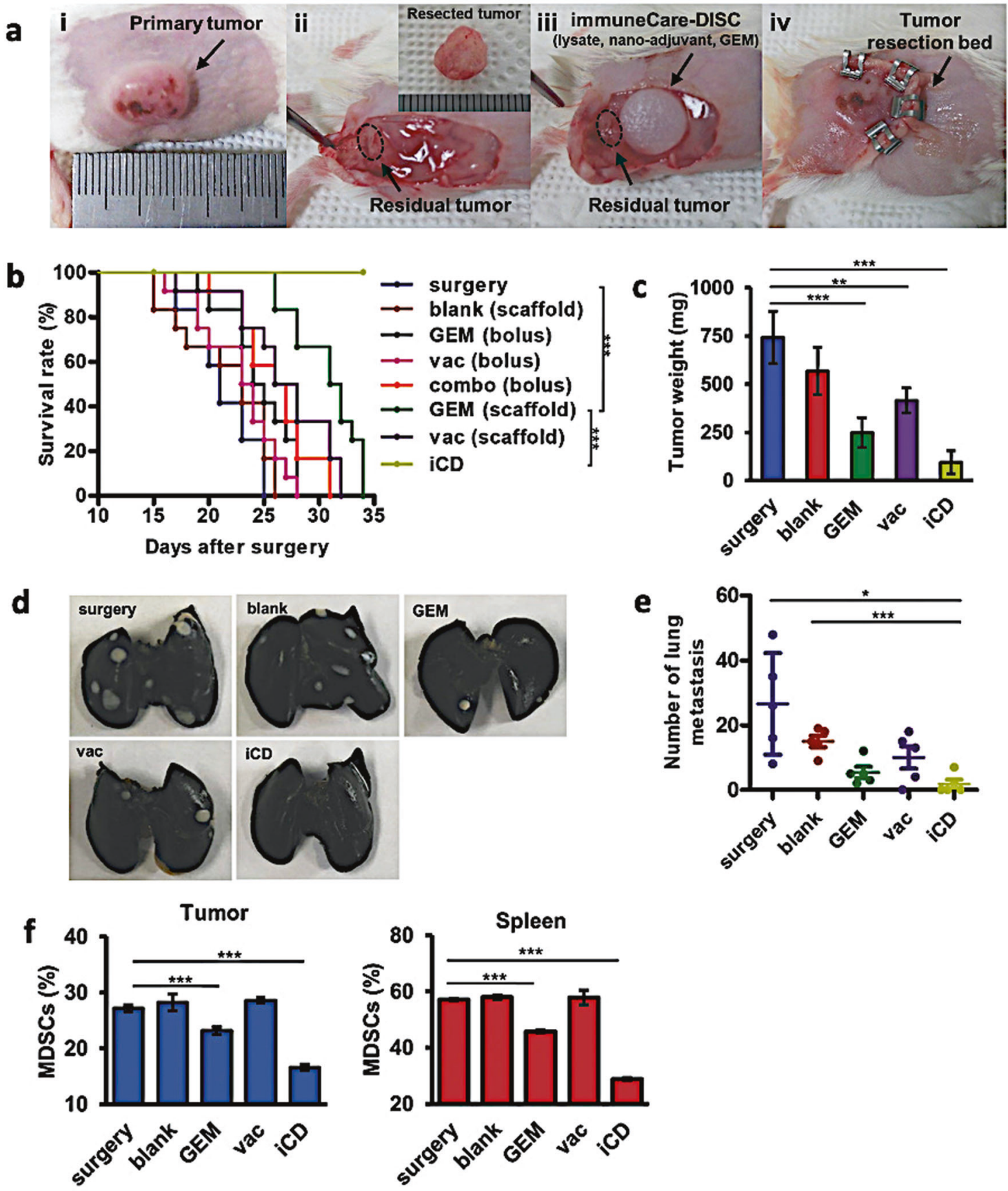

Fig. 4 a Implantation approach: (i) Surgery was performed after the tumor volume reached about $300 \mathrm{~mm}^{3}$. (ii) Tumor dissection mimicking incomplete tumor removal (about $90 \%$ of primary tumor was excised). (iii) Implantation of the iCD containing GEM and cancer vaccines. (iv) Wound closure. b Survival rate of recurrent 4T1 tumor-bearing mice determined by log-rank test $(n=10)$. c Weight of recurring tumor on day 14 after surgery. d Representative images of lungs collected from mice in the different treatment groups at days 14 after tumor resection. White nodules indicate metastatic tumors in the lungs. e The mean numbers of macroscopically visible breast cancer metastases in the lungs. f FACS analysis demonstrating infiltrating MDSCs $\left(\mathrm{CD} 11 \mathrm{~b}^{+} \mathrm{Gr} 1^{+}\right)$at day 7. Adapted from REF [103] with permission by WILEY-VCH.

the density of TAMs is associated with poor long-term survival, increased angiogenesis and metastasis $[112,113]$. Therefore, the ratio of $M 2$ to $M 1$ phenotype macrophages within tumors is a determinant of cancer immunotherapy success. In recent efforts, TAM depletion has been achieved by lipid NP-encapsulated siRNA silencing in inflammatory monocytes [114]. The technological advantages of biocompatible NPs in siRNA delivery, which are capable of systemic delivery to immune cells with nuclease stability and reduced immunostimulation, were also demonstrated. Furthermore, TAMs can be converted to the proimmunogenic M1 phenotype due to their plasticity. One study reported polarizing the protumorigenic $M 2$ phenotype toward the antitumorigenic M1 phenotype using TLR agonist-loaded NPs. R848, an agonist of TLR7/8, was used as a potent driver of the conversion of the $M 2$ to $M 1$ phenotype and loaded into $\beta$ cyclodextrin NPs (CDNP-R848) [115]. The administration of CDNPR848 modulated the tumor-supportive M2-like phenotype to its tumoricidal M1 counterpart, yielding improved immunotherapy response rates when combined with ICB and anti-PD- 1 compared with the effects of ICB alone. These findings indicate the ability of 

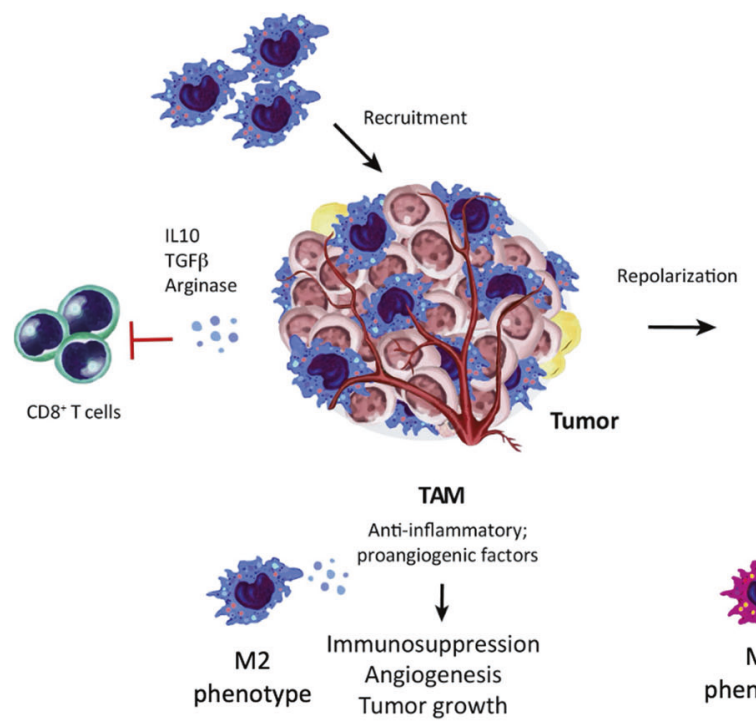

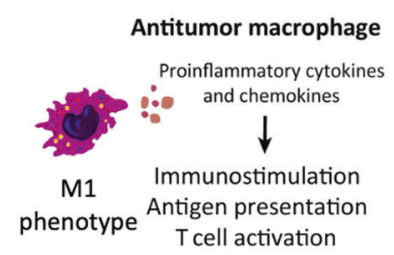

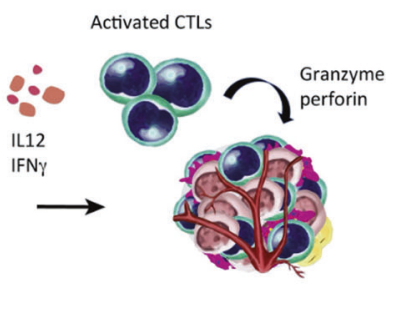

Tumor regression

Trends in Immunology

Fig. 5 Macrophages accumulate in tumors by proliferation from tissue resident precursors or by trafficking from bone marrow-derived precursors. Once in tumors, these cells can adopt a tumor-promoting phenotype (M2) that induces immunosuppression, angiogenesis, tumor growth, and metastasis. Strategies to improve cancer therapies are being tested and include (i) blocking the recruitment of TAMs; (ii) inducing the repolarization of TAMs into an immunostimulatory phenotype (M1); and (iii) upregulating antigen presentation machinery that can activate CTLs, which can then lyse malignant cells to suppress tumor growth. Adapted from REF [111] with permission by Elsevier Ltd.

drug-encapsulated NPs to efficiently modulate TAMs for cancer immunotherapy.

Effective TAM targeting is a major challenge due to a lack of high avidity and selectivity, although modulating the TME with therapeutics that deplete/reprogram TAMs has shown considerable potential. TAM targeting has been reported using NPs to improve the delivery of drugs. Small molecules, including mannose and folate, which are ligands for mannose receptor (CD206) and folate receptor $\beta$ expressed by activated M2-like macrophages, have been used as NP surface modifiers to target TAMs [116-118] and have shown enhanced cellular uptake. To increase the selectivity of TAM targeting, Yeo et al. developed polymeric NPs coated with M2pep (YEQDPWGVKWWY) that preferentially binds to murine M2-like TAMs via an adhesive layer of tannic acid-Fe ${ }^{3+}$ complex (pTA) on the NP surface (Fig. 6) [119]. M2pep-coated NP-pTA (NP-pTA-M2pep) showed increased cellular uptake by M2-polarized bone marrow-derived macrophages in vitro and $\mathrm{CD}_{206}^{+}$macrophages in B16F10 melanoma in vivo compared with that of uncoated-NPs, indicating enhanced binding affinity of M2pep-coated NPs. This group also demonstrated that tumor growth was attenuated by drug-loaded NPpTA-M2pep more than free drug in a mouse B16F10 melanoma model. These studies demonstrate that coating the NP surface with M2-like macrophage-targeting ligands facilitates the efficient delivery of drugs to TAMs with minimal effects on tumor cells.

Modulation of ECM/tumor-associated fibroblasts (TAFs)

Tumors comprise a variety of cell populations, including proliferating cancer cells, immune-stimulating/immunosuppressive cells, endothelial cells, and perivascular cells, which are embedded within a protein-rich ECM. The ECM is often dense and stiff and acts as a physical and biochemical barrier to the transport of nanomedicines. The composition and structure of the ECM not only decelerate the movement of nanomedicines but also reduce the activities of therapeutic agents. Moreover, the dense and stiff ECM increases IFP and affects the transcapillary transport and diffusion of nanomedicines in the tumor interstitium [120, 121], limiting the distribution of nanocarriers to the vicinity of perivascular regions [122]. Approaches have been proposed to overcome these challenges by enhancing the intratumoral distribution of nanomedicines. Pretreatment of tumors with hyaluronidase has been shown to degrade the ECM and induce a transcapillary pressure gradient, thereby increasing the tumor uptake of liposomal doxorubicin (DOX) [123]. Priming tumors with an apoptotic inducer was used to reduce cell density, leading to enhanced drug penetration into solid tumors [124, 125]. Jessie et al. showed that apoptosis-inducing tumor priming with PTXloaded polymeric microparticles expanded the interstitial space and resulted in a PTX concentration in tumors that was 16 times higher than the PTX/Cremophor EL (polyethoxylated castor oil) formulation and had lower toxicity [126]. In another study, Todd et al. reported that PEG surface coating of $145 \mathrm{~nm}$ radius superparamagnetic NPs improved NP transport and biodistribution by reducing nonspecific adhesion of NPs to the ECM [127].

Fibroblasts are transformed to TAFs by cytokine signaling in tumors [128], such as TGF- $\beta$ and IL-10 [129], which results in cancer progression [130] and hinders tumor-specific immunity $[131,132]$. TAFs are abundant in desmoplastic tumors and generate large quantities of ECM proteins, forming barriers that inhibit the transport of NPs [133]. Therefore, various types of NPs have been designed for TAF depletion to improve the interstitial transport and distribution of nanomedicines. For example, Huang et al. developed lipid/calcium/phosphate (LCP) NPs to facilitate improved accumulation and metabolic stability of quercetin, which suppresses the expression of Wnt16, a protein that regulates the induction of apoptosis and inhibits angiogenesis and proliferation in TAFs [134]. Quercetin prodrug-loaded LCP NPs (LCP-QP) with an average size of $35 \mathrm{~nm}$ showed greater NP penetration and tumor inhibition effects in a stroma-rich bladder carcinoma model compared with those of the parent quercetin due to a decrease in the active fibroblast population and collagen deposition in the TME. In addition, this group used similar targeted NPs with TNF-related apoptosis-inducing ligand (sTRAIL), which causes apoptosis in tumor cells, to modulate TAFs via the TGF- $\beta$ signaling pathway to treat desmoplastic cancers [135]. sTRAILloaded LCP NPs induced TAF inactivation and resulted in retarded 
a
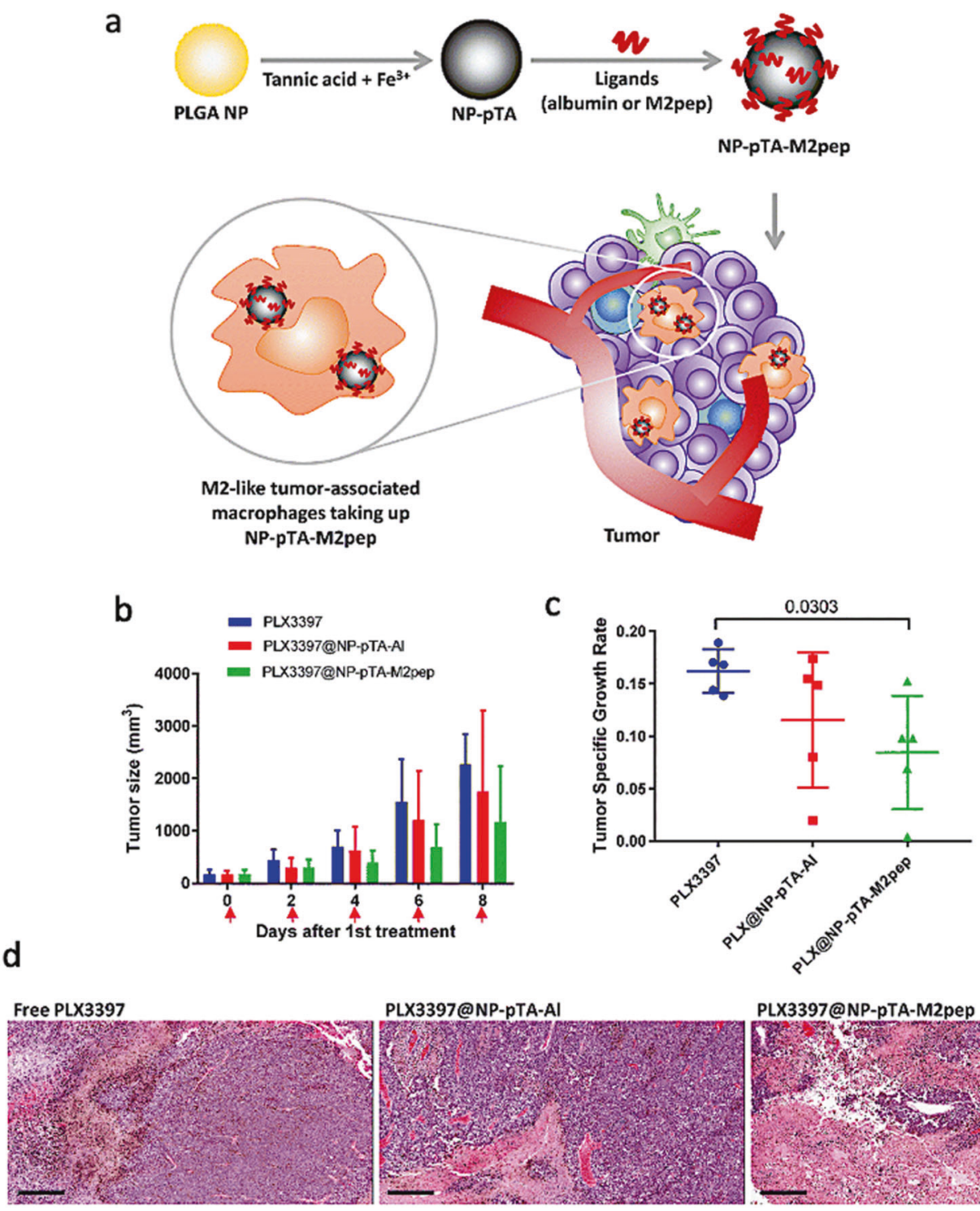

d

PLX3397@NP-pTA-AI
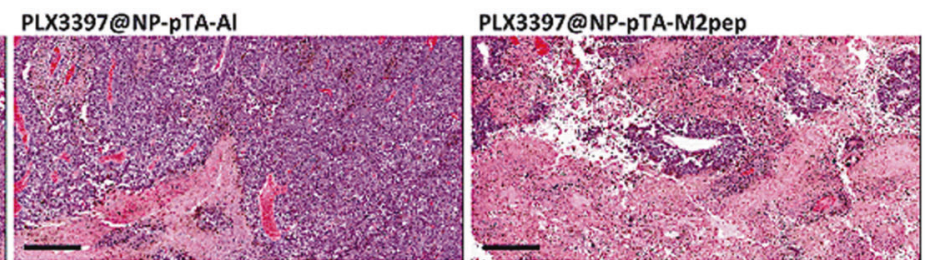

Fig. 6 a Schematic illustration of M2pep-coated NPs and their interaction with TAMs in tumor. M2pep was conjugated to PLGA NPs via a simple surface modification method based on tannic acid-iron complex. $\mathbf{b}$ Tumor volumes recorded every other day. $n=5 / \mathrm{group}$. c Specific growth rate of B16F10 tumor. $\Delta \operatorname{logV} / \Delta \mathrm{t}$ (V: tumor volumes; $\mathrm{t}$ : time in days). $p$-values by Uncorrected Fisher's LSD. $\mathbf{d}$ Histopathologic features of the tumor parenchyma treated with free PLX3397, PLX3397@NP-pTA-Al, or PLX3397@NP-pTA- M2pep. Scale bars: 300 mm: (left) free PLX3397treated tumor composed of sheets of neoplastic epithelial cells with scattered foci of necrosis and hemorrhage; (center) PLX3397@NP-pTA-Altreated tumor composed of neoplastic epithelial cells with a central core of necrosis expanded by fibroblasts, fibrin, and hemorrhage; (right) PLX3397@NP-pTA-M2pep-treated tumor composed of coalescing bands of necrosis composed of eosinophilic fibrillar material, erythrocytes, and a mixed inflammatory population. Adapted from REF [119] with permission by Springer Nature.

tumor growth. Collectively, modulating ECM/TAFs by engineered NPs is a promising strategy to favorably reduce transport barriers to drug delivery.

\section{MODULATION OF ENZYMES/CYTOKINES IN THE TME}

\section{Modulation of enzymes}

ECM-associated enzymes are elevated in the TME and are responsible for cell proliferation and differentiation, contributing to ECM stiffness and degradation [136, 137]. Matrix metalloproteases (MMPs), such as MMP-2 and MMP-9, are expressed by cancer cells and stromal cells. They exert their proteolytic activity to break down the ECM and facilitate angiogenesis, which leads to tumor progression and metastasis [136]. Accordingly, MMPs have been investigated for preventing and treating tumors; however, the delivery of MMP inhibitors has been challenging due to poor specificity. Recent studies have shown the use of NPs with potential MMP inhibitors to control metastasis in cancer therapy $[138,139]$. For example, Wang et al. created copper monosulfide nanocrystals modified with mesoporous silica and PEGylation (CuS@mSiO 2 -PEG). They found a reduction in the metastasis of cancer cells and improved survival rates after subcutaneous injections of HeLa cells that were prestimulated with Cus@mSiO $2^{-}$ PEG NPs in comparison with those of cells that were prestimulated with free copper in a HeLa lung metastasis model [138], demonstrating that NPs enhance therapeutic efficacy. Further studies have focused on a new target enzyme candidate, lysyl oxidase (LOX), which is elevated in the TME. LOX catalyzes crosslinking of collagen and elastin, which promotes stiffness of the ECM and malignancy [140,141]. One study reported coating PLGA NPs with LOX inhibitory antibody $\left(\operatorname{LOX}_{\mathrm{Ab}}\right)$ through carbodiimide chemistry (LOX ${ }_{A b} N P s$ ) to target LOX and manipulate collagen 
a

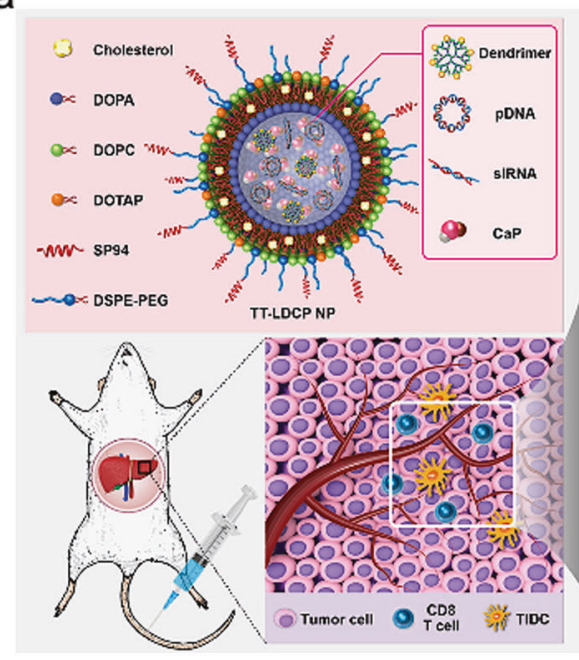

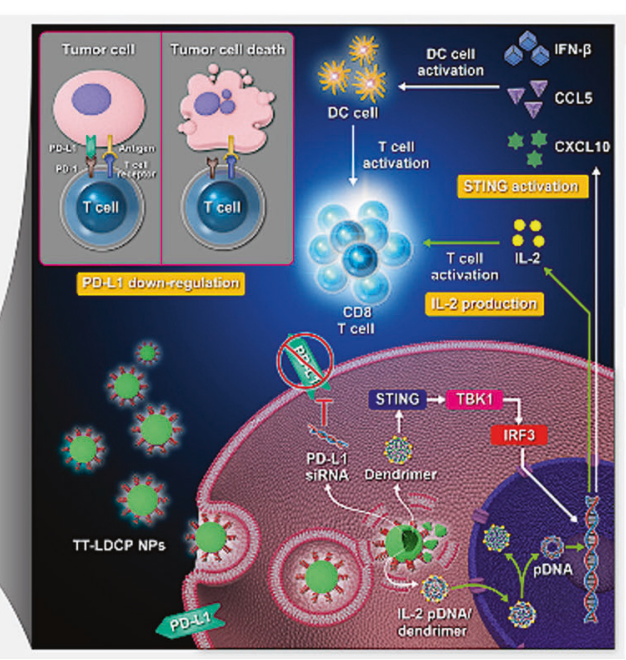

C

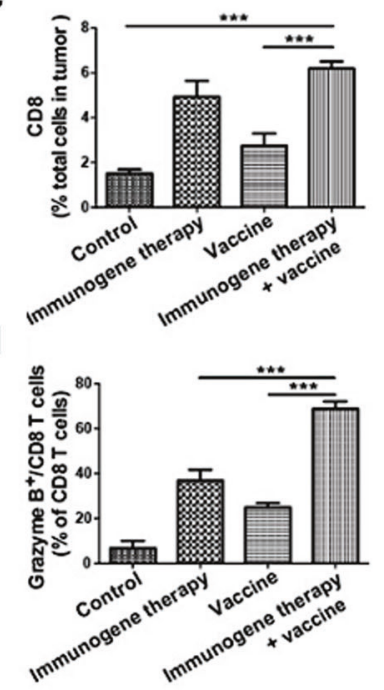

b

Immunogene therapy

IL-2 pDNA + PD-L1 siRNA

(1.2 $\mathrm{mg} / \mathrm{kg}$ ) in TT-LDCP IV

HCC orthotopic $(1.2 \mathrm{mg} / \mathrm{kg})$ in
implantation

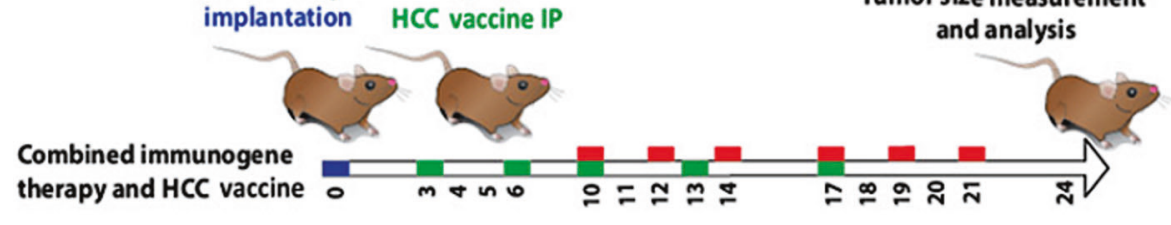

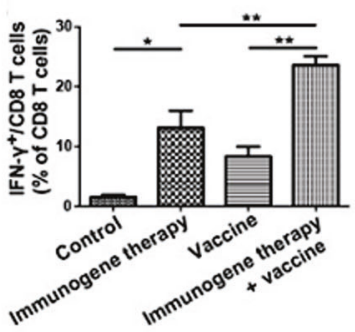

f

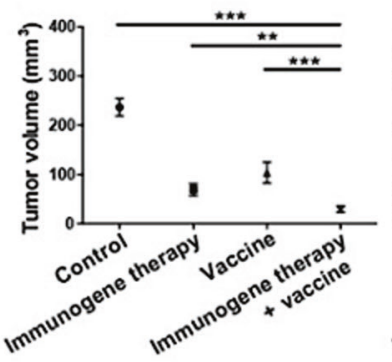

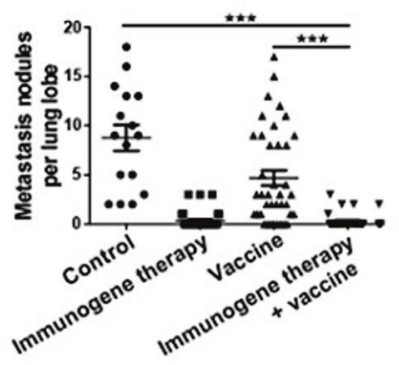

g

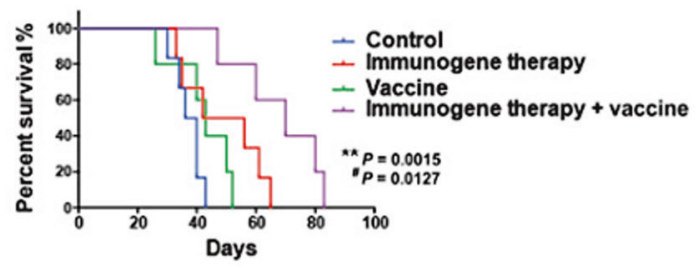

Fig. 7 a Schematic representation of the mechanism of immunogene therapy by TT-LDCP NPs containing siRNA against the immune checkpoint PD-L1 and PDNA encoding the immunostimulating cytokine IL-2. Active tumor targeting was achieved through the addition of hepatocellular carcinoma (HCC)-targeted SP94 peptide to the surface of the NPs. The thymine-capped PAMAM dendrimer/CaP complexes achieved highly efficient gene transfection efficacy by enhancing nuclear delivery of the pDNA. Furthermore, thymine-capped PAMAM dendrimers stimulate the stimulator of interferon genes (STING) pathway and serve as an adjuvant to promote the maturation of intratumoral DCs. Efficient tumor-targeted codelivery of PD-L1 siRNA and IL-2 pDNA achieves tumor-specific expression of IL-2 and downregulation of PD$\mathrm{L} 1$, increases infiltration and activation of $\mathrm{CD}^{+} \mathrm{T}$ cells in $\mathrm{HCC}$, and induces a strong tumor-suppressive effect in $\mathrm{HCC}$ in synergy with a vaccine. CaP calcium phosphate, TIDC tumor-infiltrating dendritic cell, TT-LDCP NPs tumor-targeted lipid-dendrimer-calcium-phosphate NPs, IFN- $\gamma$ interferon- $\gamma$. b Three days after the implantation of HCA-1 cells, mice were injected intraperitoneally five times (at 2- to 3-day intervals) with the HCC vaccine. For the combination groups, mice treated with the HCC vaccine received intravenous immunogene therapy (1.2 mg siRNA and pDNA/kg per dose) on days 10, 12, 14, 17, 19, and 21. Immunogene therapy: IL-2 pDNA and PD-L1 siRNA in TT-LDCP; vaccine: $5 \times 10^{6}$ mitomycin C-treated cGM-CSF-overexpressing HCA-1 cells. c Combination of immunogene therapy and the vaccine increased the number of $\mathrm{CD}^{+}$T cells in tumors, as measured by flow cytometry (control, $n=18$; immunogene therapy, $n=10$; vaccine, $n=6$; combination group, $n=$ 6). Data are means \pm SEM. d The immunofluorescence of granzyme B-positive CD8 ${ }^{+} \mathrm{T}$ cells in HCA- 1 tumors was quantified 24 days after implantation for the treatment with immunogene therapy or the HCC vaccine. (control, $n=8$; immunogene therapy, $n=6$; vaccine, $n=6$; combination group, $n=7$ ). e IFN- $\gamma$ intracellular staining in tumor-infiltrating $\mathrm{CD}^{+} \mathrm{T}$ cells measured by flow cytometry $(n=5)$. The combination of immunogene therapy and vaccine treatment significantly reduced tumor sizes (control, $n=12$; immunogene therapy, $n=12$; vaccine, $n=12$; combination group, $n=24)$ and distal lung metastatic nodules $(\mathbf{f})$ and increased the overall survival $(\mathbf{g})\left(n=5\right.$, ${ }^{* *} P<0.01$ compared with control; ${ }^{\#} P<0.05$ compared with vaccine treatment) in an orthotopic HCC model. Adapted from REF [155] with permission by AAAS under Creative Commons Attribution-NonCommercial license.

crosslinking by modulating LOX expression and/or activity [142]. The LOX ${ }_{A b} N P s$ suppressed 4 T1 tumor growth in mice to a greater extent than $\operatorname{LOX}_{\mathrm{Ab}}$ alone at the same dose $\left(50 \mu \mathrm{g} \operatorname{LOX}_{\mathrm{Ab}} / \mathrm{kg}\right)$, inhibited collagen crosslinking and suppressed ECM fibrosis in vivo. These findings also suggest that the NP formulation could achieve therapeutic efficacy by reducing the dose of soluble antibodies, thereby minimizing systemic side effects.

To restore the viability of $T$ cells in the TME, a study aimed to silence lactate dehydrogenase $\mathrm{A}$ (LDHA), an enzyme expressed by tumor cells that catalyzes the conversion of pyruvate to lactate, 
contributing to acidic pH and T-cell anergy in the TME [143]. LDHA-silencing RNAs were systemically delivered by cationic lipid NPs. This siRNA treatment efficiently downregulated LDHA levels and thus attenuated lactate accumulation and neutralized the $\mathrm{pH}$ in the TME. When combined with anti-PD1 therapy, this strategy significantly delayed tumor progression in 4T1 and B16 melanoma tumor models with a substantial increase in infiltrated antitumor $\mathrm{CD}^{+} / \mathrm{CD}^{+} \mathrm{T}$ cells and NK cells and a reduced population of T-regs in the TME.

Alternatively, inhibitors of IDO have been utilized in cancer therapy to offset immunomodulatory actions in the TME. IDO, an intracellular monomeric and heme-containing enzyme, starves the TME of Trp and increases the Trp-derived metabolite kynurenine pathway, causing immunosuppressive effects [144]. Many efforts have focused on IDO blockade treatment in combination with other immune checkpoint inhibitors to further augment antitumor activities and survival. Nie et al. developed a peptide assembling NP for the codelivery of a short d-peptide antagonist of programmed cell death-ligand-1 ('PPA-1) that binds PD-L1 and NLG919, a highly selective inhibitor of IDO [145]. By encapsulating NLG919 in NPs, this dual-targeted immunotherapeutic NP, denoted NLG919@DEAP-DPPA-1, improved the bioavailability of NLG919 and thus reduced dose-dependent toxicity. Furthermore, when injected IV in a murine model of melanoma, delayed tumor growth and extended mouse survival were observed in the NLG919@DEAP-DPPA-1 group to a greater extent than the groups treated with free NLG919 and NLG919-encapsulated DEAP NPs containing a scrambled amino acid sequence instead of the DPPA1 sequence. Another strategy involves a chemo drug, such as DOX, which can simultaneously trigger immunogenic cell death (ICD) using self-assembled liposomes composed of a phospholipidconjugated prodrug form of indoximod (IND), an IDO inhibitor [146]. The DOX-encapsulated and IND-conjugated liposomes (DOX/IND liposomes) induce ICD and increase phosphorylation of S6 kinase in the mTOR pathway, reversing the immunosuppressive activity of IDO; furthermore, the pharmacokinetics of DOX or IND were improved in the 4T1 tumor model, demonstrating the use of nanoliposomes to enhance the permeability and retention of drugs.

Modulation of cytokines

Cytokines play an important role in modulating immune responses, and an imbalance between stimulatory and suppressive cytokines causes immunosuppressive effects in the TME [147]. Although cytokines have been considered potent modulating agents for immunotherapy, many cytokines are, unfortunately, unstable and have a short half-life in circulation, resulting in poor therapeutic effects and serious side effects if delivered systemically $[148,149]$. For instance, IL-2 is an agent that is approved by the FDA for cancer immunotherapy of metastatic melanoma and renal cell carcinoma. Systemic administration of IL-2 involves the risk of adverse effects, including thrombocytopenia and lymphopenia [149]. Thus, efforts have been made to sustain and specifically deliver cytokines to tumors using NPs. One early study incorporated IL-2 into multilamellar liposome drug carriers to develop a tumor vaccine adjuvant and showed that intravenous injection of IL-2 liposomes decreased hematologic toxicities in rats, indicating that NPs are capable of reducing drug toxicity [150]. In addition, Egilmez et al. encapsulated IL-12 and/or granulocyte-macrophage colony-stimulating factor (GM-CSF) in polylactic acid microspheres to induce both innate and adaptive antitumor immune responses [151]. The combination of IL-12 and GM-CSF in microspheres was superior to treatment with either cytokine alone in enhancing antitumor immunity and long-term survival.

Despite the promise of cytokine-based therapy in cancer treatment, systemic administration of cytokines remains a challenge due to potential systemic toxicity, limiting the efficacy and dose
$[152,153]$. To overcome this challenge, researchers have adapted NP-encapsulated cytokine-encoding plasmids to modulate cytokine levels in the TME. One group generated a self-assembled NP consisting of methoxy poly(ethylene glycol)-poly(lactide) (MPEGPLA) and 1,2-dioleoyl-3-trimethylammonium-propan, named DMP, with a zeta-potential value of $38.5 \mathrm{mV}$ and a size of $37.5 \mathrm{~nm}$ for delivery of the IL-12 plasmid (plL12), which can activate innate and adaptive immunity [154]. The plL12 and DMP complex significantly inhibited tumor growth by suppressing tumor angiogenesis, promoting apoptosis and reducing proliferation in both subcutaneous and peritoneal colon cancer models, with increased expression of IL-12 in the absence of noticeable adverse effects induced by IL-12, demonstrating the potential of cytokine gene delivery nanocarriers. Another interesting approach to improving anticancer efficacy and circumventing systemic toxicity was reported using tumor-targeted lipid-dendrimer-calcium-phosphate (TT-LDCP) NPs [155]. Chen et al. designed tumor-targeting lipid NPs to deliver siRNA against the immune checkpoint ligand PD-L1 and immunostimulatory IL-2-encoding plasmid DNA, which reprogrammed the TME and synergized with a hepatoma vaccine by increasing tumor-infiltrating $\mathrm{CD}^{+} \mathrm{T}$ cells and the expression of IFN$\gamma$ and granzyme $B$, resulting in significantly improved antitumor efficacy compared with that of vaccine alone (Fig. 7). These results demonstrated the potential of immune gene therapy to modulate the TME.

\section{CONCLUDING REMARKS}

The recent successes of several immunotherapeutic agents in the clinic have motivated the field to optimize current approaches to tackle unresolved issues, such as limited responses to immunotherapy [156], development of resistance [157], and toxicities associated with therapies including ICB, cytokine therapy and CAR-T cell infusion [158-160]. In the past several decades, cancer nanomedicine has confronted similar problems, and those experiences could be utilized to improve current immunotherapies. As we reviewed here, nanoenabled delivery systems can reprogram the TME and thus hold great promise to amplify antitumor immune responses.

Immune context in the TME is the medium in which immunotherapies struggle to triumph. Controversies still exist regarding the influence of altered metabolism on the development and functions of infiltrated immune cells [88, 161]. Several metabolic targets in the TME and ligands have been identified; however, optimal delivery strategies still need further development $[10,162]$. In addition to the aforementioned immune cells, the functions of tumor-infiltrated $B$ cells remain inadequately explored. Clinical data indicate that the enrichment of $\mathrm{CD} 2 \mathrm{O}^{+} \mathrm{B}$ cells in the TME is associated with improved immunotherapeutic responses and survival in patients with melanoma, sarcoma, or renal cell carcinoma who received ICB [163-165]. In addition, accumulating clinical evidence has demonstrated the correlation between increased density of intratumoral tertiary lymphoid structures (TLSs) and the positive responses of patients to chemoor immunotherapies, suggesting that TLS formation could be exploited as a prognostic indicator of tumor sensitivity to treatments [164]. Studies have also proven that TLSs serve as shelters for immune cells under attack by the TME and can support the antigen presentation and education of infiltrated $T$ and $B$ cells and hence enhance antitumor immunity [166]. The importance of TLSs has been recognized, and strategies that promote TLS neogenesis may represent a promising direction for cancer therapy.

\section{ACKNOWLEDGEMENTS}

This work was supported by funding from National Institutes of Health (U54CA198999 and R01 CA178748), Department of Defense Congressionally Directed Medical Research 
Programs-Peer Reviewed Cancer Research Program Idea Award (CA150391), and The University of North Carolina Research Opportunity Initiative grant.

\section{ADDITIONAL INFORMATION}

Competing interests: The authors declare no competing interests.

\section{REFERENCES}

1. Liotta LA, Kohn EC. The microenvironment of the tumour-host interface. Nature. 2001:411:375-9.

2. Wagner J, Rapsomaniki MA, Chevrier S, Anzeneder T, Langwieder C, Dykgers A, et al. A Single-cell atlas of the tumor and immune ecosystem of human breast cancer. Cell. 2019;177:1330-45.

3. Tamura R, Tanaka T, Akasaki Y, Murayama Y, Yoshida K, Sasaki H. The role of vascular endothelial growth factor in the hypoxic and immunosuppressive tumor microenvironment: perspectives for therapeutic implications. Med Oncol. 2019;37:2.

4. Less JR, Skalak TC, Sevick EM, Jain RK. Microvascular architecture in a mammary carcinoma: branching patterns and vessel dimensions. Cancer Res. 1991;51:265-73.

5. Munn LL. Aberrant vascular architecture in tumors and its importance in drugbased therapies. Drug Discov Today. 2003;8:396-403.

6. Vaupel P, Mayer A. Hypoxia in cancer: significance and impact on clinical outcome. Cancer Metastasis Rev. 2007;26:225-39.

7. Romero-Garcia S, Lopez-Gonzalez JS, B'ez-Viveros JL, Aguilar-Cazares D, PradoGarcia H. Tumor cell metabolism. Cancer Biol Ther. 2011;12:939-48.

8. Stubbs M, McSheehy PMJ, Griffiths JR, Bashford CL. Causes and consequences of tumour acidity and implications for treatment. Mol Med Today. 2000;6:15-9.

9. Lee ES, Oh KT, Kim D, Youn YS, Bae YH. Tumor pH-responsive flower-like micelles of poly(l-lactic acid)-b-poly(ethylene glycol)-b-poly(l-histidine). J Control Release. 2007;123:19-26.

10. Abdel-Wahab AF, Mahmoud W, Al-Harizy RM. Targeting glucose metabolism to suppress cancer progression: prospective of anti-glycolytic cancer therapy. Pharmacol Res. 2019;150:104511.

11. Jain RK, Martin JD, Stylianopoulos T. The role of mechanical forces in tumor growth and therapy. Annu Rev Biomed Eng. 2014;16:321-46.

12. Nicolas-Boluda A, Silva AKA, Fournel S, Gazeau F. Physical oncology: new targets for nanomedicine. Biomaterials. 2018;150:87-99.

13. Kobayashi H, Watanabe R, Choyke PL. Improving conventional enhanced permeability and retention (EPR) effects; what is the appropriate target? Theranostics. 2013;4:81-9.

14. Engblom C, Pfirschke C, Pittet MJ. The role of myeloid cells in cancer therapies. Nat Rev Cancer. 2016;16:447-62.

15. Gun SY, Lee SWL, Sieow JL, Wong SC. Targeting immune cells for cancer therapy. Redox Biol. 2019;25:101174.

16. Hinshaw DC, Shevde LA. The tumor microenvironment innately modulates cancer progression. Cancer Res. 2019;79:4557-66.

17. Magalhaes I, Yogev O, Mattsson J, Schurich A. The metabolic profile of tumor and virally infected cells shapes their microenvironment counteracting $T$ cell immunity. Front Immunol. 2019;10:2309.

18. Srivastava MK, Sinha $P$, Clements VK, Rodriguez $P$, Ostrand-Rosenberg $S$. Myeloid-derived suppressor cells inhibit T-cell activation by depleting cystine and cysteine. Cancer Res. 2010;70:68-77.

19. Pearce EL, Walsh MC, Cejas PJ, Harms GM, Shen H, Wang LS, et al. Enhancing CD8 T-cell memory by modulating fatty acid metabolism. Nature. 2009;460: 103-7.

20. Ho P-C, Bihuniak Jessica D, Macintyre Andrew N, Staron M, Liu X, Amezquita R, et al. Phosphoenolpyruvate is a metabolic checkpoint of anti-tumor $\mathrm{T}$ cell responses. Cell. 2015;162:1217-28.

21. Chang $\mathrm{CH}$, Curtis Jonathan D, Maggi Leonard B, Faubert B, Villarino Alejandro V, O'Sullivan $D$, et al. Posttranscriptional control of $T$ cell effector function by aerobic glycolysis. Cell. 2013;153:1239-51.

22. Chang $C H$, Qiu J, O'Sullivan D, Buck Michael D, Noguchi T, Curtis Jonathan $D$, et al. Metabolic competition in the tumor microenvironment is a driver of cancer progression. Cell. 2015;162:1229-41.

23. Mescher MF, Curtsinger JM, Agarwal P, Casey KA, Gerner M, Hammerbeck CD, et al. Signals required for programming effector and memory development by $\mathrm{CD}^{+}$T cells. Immunol Rev. 2006;211:81-92.

24. Crespo J, Sun H, Welling TH, Tian Z, Zou W. T cell anergy, exhaustion, senescence, and stemness in the tumor microenvironment. Curr Opin Immunol. 2013;25:214-21.

25. Das M, Zhu C, Kuchroo VK. Tim-3 and its role in regulating anti-tumor immunity. Immunol Rev. 2017;276:97-111.
26. Vivier E, Raulet DH, Moretta A, Caligiuri MA, Zitvogel L, Lanier LL, et al. Innate or adaptive immunity? The example of natural killer cells. Science. 2011;331:44-9.

27. Boieri M, Ulvmoen A, Sudworth A, Lendrem C, Collin M, Dickinson AM, et al. IL12 IL-15, and IL-18 pre-activated NK cells target resistant $T$ cell acute lymphoblastic leukemia and delay leukemia development in vivo. Oncolmmunology. 2017;6:e1274478.

28. Lusty E, Poznanski SM, Kwofie K, Mandur TS, Lee DA, Richards CD, et al. IL-18/IL15/IL-12 synergy induces elevated and prolonged IFN- $\gamma$ production by ex vivo expanded NK cells which is not due to enhanced STAT4 activation. Mol Immunol. 2017;88:138-47.

29. Cong J, Wang X, Zheng X, Wang D, Fu B, Sun R, et al. Dysfunction of natural killer cells by $\mathrm{FBP} 1$-induced inhibition of glycolysis during lung cancer progression. Cell Metab. 2018;28:243-55.

30. Mah AY, Cooper MA. Metabolic regulation of natural killer cell IFN- $\gamma$ production. Crit Rev Immunol. 2016;36:131-47.

31. Young A, Ngiow SF, Gao Y, Patch AM, Barkauskas DS, Messaoudene M, et al. A2AR adenosine signaling suppresses natural killer cell maturation in the tumor microenvironment. Cancer Res. 2018;78:1003-16.

32. Brand A, Singer K, Koehl Gudrun E, Kolitzus M, Schoenhammer G, Thiel A, et al. LDHA-associated lactic acid production blunts tumor immunosurveillance by $T$ and NK cells. Cell Metab. 2016;24:657-71.

33. Kedia-Mehta N, Finlay DK. Competition for nutrients and its role in controlling immune responses. Nat Commun. 2019;10:2123.

34. Walls J, Sinclair L, Finlay D. Nutrient sensing, signal transduction and immune responses. Semin Immunol. 2016;28:396-407.

35. Chiesa MD, Carlomagno S, Frumento G, Balsamo M, Cantoni C, Conte R, et al. The tryptophan catabolite I-kynurenine inhibits the surface expression of NKp46- and NKG2D-activating receptors and regulates NK-cell function. Blood. 2006;108:4118-25.

36. Liu X, Shin N, Koblish HK, Yang G, Wang Q, Wang K, et al. Selective inhibition of IDO1 effectively regulates mediators of antitumor immunity. Blood. 2010; 115:3520-30.

37. Vitale M, Cantoni C, Pietra G, Mingari MC, Moretta L. Effect of tumor cells and tumor microenvironment on NK-cell function. Eur J Immunol. 2014;44:1582-92.

38. Gabrilovich DI. Myeloid-derived suppressor cells. Cancer Immunol Res. 2017; 5:3-8.

39. Cassetta L, Fragkogianni S, Sims AH, Swierczak A, Forrester LM, Zhang $H$, et al. Human tumor-associated macrophage and monocyte transcriptional landscapes reveal cancer-specific reprogramming, biomarkers, and therapeutic targets. Cancer Cell. 2019;35:588-602.

40. Henze AT, Mazzone M. The impact of hypoxia on tumor-associated macrophages. J Clin Investig. 2016;126:3672-9.

41. Mantovani A, Marchesi F, Malesci A, Laghi L, Allavena P. Tumour-associated macrophages as treatment targets in oncology. Nat Rev Clin Oncol. 2017;14: 399-416.

42. Jeong $\mathrm{H}$, Kim S, Hong BJ, Lee $\mathrm{CJ}$, Kim YE, Bok S, et al. Tumor-associated macrophages enhance tumor hypoxia and aerobic glycolysis. Cancer Res. 2019; 79:795-806.

43. Ye H, Zhou Q, Zheng S, Li G, Lin Q, Wei L, et al. Tumor-associated macrophages promote progression and the Warburg effect via CCL18/NF-kB/NCAM-1 pathway in pancreatic ductal adenocarcinoma. Cell Death Dis. 2018;9:453.

44. Peranzoni E, Lemoine J, Vimeux L, Feuillet V, Barrin S, Kantari-Mimoun C, et al. Macrophages impede CD8 $T$ cells from reaching tumor cells and limit the efficacy of anti-PD-1 treatment. Proc Natl Acad Sci. 2018;115:4041-50.

45. Mazzone M, Menga A, Castegna A. Metabolism and TAM functions-it takes two to tango. FEBS J. 2018;285:700-16.

46. Cassetta L, Pollard JW. Targeting macrophages: therapeutic approaches in cancer. Nat Rev Drug Discov. 2018;17:887-904.

47. Barsoum IB, Koti M, Siemens DR, Graham CH. Mechanisms of hypoxia-mediated immune escape in cancer. Cancer Res. 2014;74:7185-90.

48. Vuillefroy de Silly R, Dietrich PY, Walker PR. Hypoxia and antitumor CD8 ${ }^{+}$T cells: an incompatible alliance? Oncoimmunology. 2016;5:e1232236.

49. Yonezawa A, Dutt S, Chester C, Kim J, Kohrt HE. Boosting cancer immunotherapy with anti-CD137 antibody therapy. Clin Cancer Res. 2015;21:3113-20.

50. Palazón A, Martínez-Forero I, Teijeira A, Morales-Kastresana A, Alfaro C, Sanmamed MF, et al. The HIF-1a hypoxia response in tumor-infiltrating $T$ lymphocytes induces functional CD137 (4-1BB) for immunotherapy. Cancer Discov. 2012;2:608-23.

51. Balsamo M, Manzini C, Pietra G, Raggi F, Blengio F, Mingari MC, et al. Hypoxia downregulates the expression of activating receptors involved in NK-cell-mediated target cell killing without affecting ADCC. Eur J Immunol. 2013;43:2756-64.

52. Parodi M, Raggi F, Cangelosi D, Manzini C, Balsamo M, Blengio F, et al. Hypoxia modifies the transcriptome of human NK cells, modulates their immunoregulatory profile, and influences NK cell subset migration. Front Immunol. 2018;9:2358. 
53. Anselmo AC, Mitragotri S. Nanoparticles in the clinic. Bioeng Transl Med. 2016; $1: 10-29$.

54. Lou J, Zhang L, Zheng G. Advancing cancer immunotherapies with nanotechnology. Adv Ther. 2019;2:1800128.

55. Locy H, de Mey S, de Mey W, De Ridder M, Thielemans K, Maenhout SK. Immunomodulation of the tumor microenvironment: turn foe into friend. Front Immunol. 2018;9:2909.

56. Jiang S, Yan W. T-cell immunometabolism against cancer. Cancer Lett. 2016;382:255-8.

57. Patel $\mathrm{CH}$, Powell JD. Targeting $\mathrm{T}$ cell metabolism to regulate $\mathrm{T}$ cell activation, differentiation and function in disease. Curr Opin Immunol. 2017:46:82-8.

58. Yang W, Bai $Y$, Xiong $Y$, Zhang J, Chen S, Zheng $X$, et al. Potentiating the antitumour response of $\mathrm{CD}^{+} \mathrm{T}$ cells by modulating cholesterol metabolism. Nature. 2016;531:651-5

59. Zhang Y, Kurupati R, Liu L, Zhou XY, Zhang G, Hudaihed A, et al. Enhancing $\mathrm{CD}^{+} \mathrm{T}$ cell fatty acid catabolism within a metabolically challenging tumor microenvironment increases the efficacy of melanoma immunotherapy. Cancer Cell. 2017;32:377-91.

60. Li M, Yang Y, Wei J, Cun X, Lu Z, Qiu Y, et al. Enhanced chemo-immunotherapy against melanoma by inhibition of cholesterol esterification in $\mathrm{CD}^{+} \mathrm{T}$ cells. Nanomedicine. 2018;14:2541-50.

61. Mi Y, Smith CC, Yang F, Qi Y, Roche KC, Serody JS, et al. A dual immunotherapy nanoparticle improves T-cell activation and cancer immunotherapy. Adv Mater. 2018;30:e1706098.

62. Choi BK, Lee DY, Lee DG, Kim YH, Kim SH, Oh HS, et al. 4-1BB signaling activates glucose and fatty acid metabolism to enhance $\mathrm{CD}^{+} \mathrm{T}$ cell proliferation. Cell $\mathrm{Mol}$ Immunol. 2017;14:748-57.

63. Galstyan A, Markman JL, Shatalova ES, Chiechi A, Korman AJ, Patil R, et al. Bloodbrain barrier permeable nano immunoconjugates induce local immune responses for glioma therapy. Nat Commun. 2019;10:3850.

64. Isaacs JD, Burrows N, Wing M, Keogan MT, Rebello P, Watts RA, et al. Humanized anti-CD4 monoclonal antibody therapy of autoimmune and inflammatory disease. Clin Exp Immunol. 1997;110:158-66.

65. Choi BK, Kim YH, Kang WJ, Lee SK, Kim KH, Shin SM, et al. Mechanisms involved in synergistic anticancer immunity of anti-4-1BB and anti-CD4 therapy. Cancer Res. 2007;67:8891-9.

66. Trifari S, Kaplan CD, Tran EH, Crellin NK, Spits H. Identification of a human helper $\mathrm{T}$ cell population that has abundant production of interleukin 22 and is distinct from TH-17, TH1 and TH2 cells. Nat Immunol. 2009;10:864-71.

67. Zhu J, Paul WE. CD4 T cells: fates, functions, and faults. Blood. 2008;112:1557-69.

68. Crotty S. Follicular helper CD4 T cells (TFH). Annu Rev Immunol. 2011;29:621-63.

69. Geginat J, Paroni M, Maglie S, Alfen JS, Kastirr I, Gruarin P, et al. Plasticity of human CD4 T cell subsets. Front Immunol. 2014;5:630.

70. National Cancer Institute. FDA approves second CAR T-cell therapy for lymphoma. Accessed 16 Apr 2020. https://www.cancer.gov/news-events/cancercurrents-blog/2018/tisagenlecleucel-fda-lymphoma.

71. Tang L, Zheng Y, Melo MB, Mabardi L, Castaño AP, Xie YQ, et al. Enhancing T cell therapy through TCR-signaling-responsive nanoparticle drug delivery. Nat Biotechnol. 2018;36:707-16.

72. Zhang F, Stephan SB, Ene Cl, Smith TT, Holland EC, Stephan MT. Nanoparticles that reshape the tumor milieu create a therapeutic window for effective T-cell therapy in solid malignancies. Cancer Res. 2018;78:3718-30.

73. Kouidhi S, Elgaaied AB, Chouaib S. Impact of metabolism on T-cell differentiation and function and cross talk with tumor microenvironment. Front Immunol. 2017;8:270.

74. Miska J, Lee-Chang C, Rashidi A, Muroski ME, Chang AL, Lopez-Rosas A, et al. HIF-1a is a metabolic switch between glycolytic-driven migration and oxidative phosphorylation-driven immunosuppression of Tregs in glioblastoma. Cell Rep. 2019:27:226-37.

75. Liu X, Mo W, Ye J, Li L, Zhang Y, Hsueh EC, et al. Regulatory T cells trigger effector T cell DNA damage and senescence caused by metabolic competition. Nat Commun. 2018;9:249.

76. Pacella I, Procaccini C, Focaccetti C, Miacci S, Timperi E, Faicchia D, et al. Fatty acid metabolism complements glycolysis in the selective regulatory $\mathrm{T}$ cell expansion during tumor growth. Proc Natl Acad Sci U S A. 2018;115:6546-55.

77. Muroski ME, Miska J, Chang AL, Zhang P, Rashidi A, Moore H, et al. Fatty acid uptake in T cell subsets using a quantum dot fatty acid conjugate. Sci Rep. 2017;7:5790.

78. Cluxton D, Petrasca A, Moran B, Fletcher JM. Differential regulation of human Treg and Th17 cells by fatty acid synthesis and glycolysis. Front Immunol. 2019;10:115.

79. Caster JM, Callaghan C, Seyedin SN, Henderson K, Sun B, Wang AZ. Optimizing advances in nanoparticle delivery for cancer immunotherapy. Adv Drug Deliv Rev. 2019;144:3-15.

80. Pacella I, Piconese S. Immunometabolic checkpoints of Treg dynamics: adaptation to microenvironmental opportunities and challenges. Front Immunol. 2019;10:1889.
81. Zappasodi R, Sirard C, Li Y, Budhu S, Abu-Akeel M, Liu C, et al. Rational design of anti-GITR-based combination immunotherapy. Nat Med. 2019;25:759-66.

82. Mahne AE, Mauze S, Joyce-Shaikh B, Xia J, Bowman EP, Beebe AM, et al. Dual roles for regulatory $\mathrm{T}$-cell depletion and costimulatory signaling in agonistic GITR targeting for tumor immunotherapy. Cancer Res. 2017;77:1108-18.

83. Schoenhals JE, Cushman TR, Barsoumian HB, Li A, Cadena AP, Niknam S, et al. Anti-glucocorticoid-induced tumor necrosis factor-related protein (GITR) therapy overcomes radiation-induced Treg immunosuppression and drives abscopal effects. Front Immunol. 2018;9:2170.

84. Balachandran VP, Cavnar MJ, Zeng S, Bamboat ZM, Ocuin LM, Obaid H, et al. Imatinib potentiates antitumor $\mathrm{T}$ cell responses in gastrointestinal stromal tumor through the inhibition of IDO. Nat Med. 2011;17:1094-100.

85. Larmonier $\mathrm{N}$, Janikashvili $\mathrm{N}$, LaCasse $\mathrm{CJ}$, Larmonier $\mathrm{CB}$, Cantrell J, Situ $\mathrm{E}$, et al. Imatinib mesylate inhibits $\mathrm{CD} 4{ }^{+} \mathrm{CD} 25^{+}$regulatory $\mathrm{T}$ cell activity and enhances active immunotherapy against BCR-ABL-tumors. J Immunol. 2008;181:6955-63.

86. Ou W, Jiang L, Thapa RK, Soe ZC, Poudel K, Chang JH, et al. Combination of NIR therapy and regulatory $\mathrm{T}$ cell modulation using layer-by-layer hybrid nanoparticles for effective cancer photoimmunotherapy. Theranostics. 2018;8:4574-90.

87. Gabrilovich DI, Ostrand-Rosenberg S, Bronte V. Coordinated regulation of myeloid cells by tumours. Nat Rev Immunol. 2012;12:253-68.

88. Kumar V, Patel S, Tcyganov E, Gabrilovich DI. The nature of myeloid-derived suppressor cells in the tumor microenvironment. Trends Immunol. 2016:37:208-20.

89. Hossain F, Al-Khami AA, Wyczechowska D, Hernandez C, Zheng L, Reiss K, et al. Inhibition of fatty acid oxidation modulates immunosuppressive functions of myeloid-derived suppressor cells and enhances cancer therapies. Cancer Immunol Res. 2015;3:1236-47.

90. Huang B, Pan P-Y, Li Q, Sato Al, Levy DE, Bromberg J, et al. Gr- $1^{+} \mathrm{CD} 115^{+}$ immature myeloid suppressor cells mediate the development of tumor-induced $\mathrm{T}$ regulatory cells and T-cell anergy in tumor-bearing host. Cancer Res. 2006;66:1123-31.

91. Yang R, Cai Z, Zhang Y, Yutzy WH, Roby KF, Roden RBS. CD80 in immune suppression by mouse ovarian carcinoma-associated $\mathrm{Gr}-1^{+} \mathrm{CD} 11 \mathrm{~b}^{+}$myeloid cells. Cancer Res. 2006;66:6807-15.

92. Kodumudi KN, Woan K, Gilvary DL, Sahakian E, Wei S, Djeu JY. A novel chemoimmunomodulating property of docetaxel: suppression of myeloid-derived suppressor cells in tumor bearers. Clin Cancer Res. 2010;16:4583-94.

93. Yang WC, Ma G, Chen SH, Pan PY. Polarization and reprogramming of myeloidderived suppressor cells. J Mol Cell Biol. 2013;5:207-9.

94. Waldron TJ, Quatromoni JG, Karakasheva TA, Singhal S, Rustgi AK. Myeloid derived suppressor cells. Oncolmmunology. 2013;2:e24117.

95. Li S, Sun R, Chen Y, Wei H, Tian Z. TLR2 limits development of hepatocellular carcinoma by reducing IL18-mediated immunosuppression. Cancer Res. 2015;75:986-95.

96. Forghani P, Waller EK. Poly (I: C) modulates the immunosuppressive activity of myeloid-derived suppressor cells in a murine model of breast cancer. Breast Cancer Res Treat. 2015;153:21-30.

97. Zoglmeier C, Bauer H, Nörenberg D, Wedekind G, Bittner P, Sandholzer N, et al. CpG blocks immunosuppression by myeloid-derived suppressor cells in tumorbearing mice. Clin Cancer Res. 2011;17:1765-75.

98. He W, Liang P, Guo G, Huang Z, Niu Y, Dong L, et al. Re-polarizing myeloidderived suppressor cells (MDSCs) with cationic polymers for cancer immunotherapy. Sci Rep. 2016;6:24506

99. Chen $\mathrm{H}$, Li P, Yin Y, Cai X, Huang Z, Chen J, et al. The promotion of type $1 \mathrm{~T}$ helper cell responses to cationic polymers in vivo via toll-like receptor-4 mediated IL-12 secretion. Biomaterials. 2010;31:8172-80.

100. Plebanek MP, Bhaumik D, Bryce PJ, Thaxton CS. Scavenger receptor type B1 and lipoprotein nanoparticle inhibit myeloid-derived suppressor cells. Mol Cancer Ther. 2018;17:686-97.

101. Sasso MS, Lollo G, Pitorre M, Solito S, Pinton L, Valpione $S$, et al. Low dose gemcitabine-loaded lipid nanocapsules target monocytic myeloid-derived suppressor cells and potentiate cancer immunotherapy. Biomaterials. 2016;96:47-62.

102. Zhou J, Donatelli SS, Gilvary DL, Tejera MM, Eksioglu EA, Chen X, et al. Therapeutic targeting of myeloid-derived suppressor cells involves a novel mechanism mediated by clusterin. Sci Rep. 2016;6:29521.

103. Phuengkham H, Song C, Um SH, Lim YT. Implantable synthetic immune niche for spatiotemporal modulation of tumor-derived immunosuppression and systemic antitumor immunity: postoperative immunotherapy. Adv Mater. 2018;30:e1706719.

104. Ozao-Choy J, Ma G, Kao J, Wang GX, Meseck M, Sung M, et al. The novel role of tyrosine kinase inhibitor in the reversal of immune suppression and modulation of tumor microenvironment for immune-based cancer therapies. Cancer Res. 2009:69:2514-22.

105. Draghiciu O, Nijman HW, Hoogeboom BN, Meijerhof T, Daemen T. Sunitinib depletes myeloid-derived suppressor cells and synergizes with a cancer vaccine to enhance antigen-specific immune responses and tumor eradication. Oncolmmunology. 2015:4:e989764. 
106. Farsaci B, Higgins JP, Hodge JW. Consequence of dose scheduling of sunitinib on host immune response elements and vaccine combination therapy. Int J Cancer. 2012;130:1948-59.

107. Huo M, Zhao Y, Satterlee AB, Wang Y, Xu Y, Huang L. Tumor-targeted delivery of sunitinib base enhances vaccine therapy for advanced melanoma by remodeling the tumor microenvironment. J Control Release. 2017;245:81-94.

108. Zhao Y, Huo M, Xu Z, Wang Y, Huang L. Nanoparticle delivery of CDDO-Me remodels the tumor microenvironment and enhances vaccine therapy for melanoma. Biomaterials. 2015;68:54-66.

109. Noy R, Pollard JW. Tumor-associated macrophages: from mechanisms to therapy. Immunity. 2014;41:49-61.

110. Mosser DM, Edwards JP. Exploring the full spectrum of macrophage activation. Nat Rev Immunol. 2008;8:958-69.

111. Pathria $P$, Louis $T L$, Varner JA. Targeting tumor-associated macrophages in cancer. Trends Immunol. 2019;40:310-27.

112. Sawa-Wejksza K, Kandefer-Szerszen M. Tumor-associated macrophages as target for antitumor therapy. Arch Immunol Ther Exp. 2018;66:97-111.

113. Qian BZ, Pollard JW. Macrophage diversity enhances tumor progression and metastasis. Cell. 2010;141:39-51.

114. Leuschner F, Dutta P, Gorbatov R, Novobrantseva TI, Donahoe JS, Courties G, et al. Therapeutic siRNA silencing in inflammatory monocytes in mice. Nat Biotechnol. 2011;29:1005-10.

115. Rodell CB, Arlauckas SP, Cuccarese MF, Garris CS, Li R, Ahmed MS, et al. TLR7/8agonist-loaded nanoparticles promote the polarization of tumour-associated macrophages to enhance cancer immunotherapy. Nat Biomed Eng. 2018;2:578-88.

116. Yu SS, Lau CM, Barham WJ, Onishko HM, Nelson CE, Li H, et al. Macrophagespecific RNA interference targeting via "click", mannosylated polymeric micelles. Mol Pharmacol. 2013;10:975-87.

117. Turk MJ, Waters DJ, Low PS. Folate-conjugated liposomes preferentially target macrophages associated with ovarian carcinoma. Cancer Lett. 2004;213:165-72.

118. Ai SL, He XY, Liu BY, Zhuo RX, Cheng SX. Targeting delivery of oligodeoxynucleotides to macrophages by mannosylated cationic albumin for immune stimulation in cancer treatment. Mol Pharmacol. 2019;16:2616-25.

119. Pang L, Pei $Y$, Uzunalli G, Hyun H, Lyle LT, Yeo Y. Surface modification of polymeric nanoparticles with M2pep peptide for drug delivery to tumorassociated macrophages. Pharmacol Res. 2019;36:65.

120. Jain RK. Transport of molecules in the tumor interstitium: a review. Cancer Res. 1987;47:3039-51.

121. Heldin $\mathrm{CH}$, Rubin $\mathrm{K}$, Pietras $\mathrm{K}$, Ostman A. High interstitial fluid pressure-an obstacle in cancer therapy. Nat Rev Cancer. 2004;4:806-13.

122. Paszek MJ, Zahir N, Johnson KR, Lakins JN, Rozenberg Gl, Gefen A, et al. Tensional homeostasis and the malignant phenotype. Cancer Cell. 2005;8:241-54.

123. Eikenes L, Tari M, Tufto I, Bruland OS, de Lange Davies C. Hyaluronidase induces a transcapillary pressure gradient and improves the distribution and uptake of liposomal doxorubicin (Caelyx) in human osteosarcoma xenografts. Br J Cancer. 2005;93:81-8.

124. Jang SH, Wientjes MG, Au JL. Determinants of paclitaxel uptake, accumulation and retention in solid tumors. Invest N Drugs. 2001;19:113-23.

125. Jang SH, Wientjes MG, Au JL. Enhancement of paclitaxel delivery to solid tumors by apoptosis-inducing pretreatment: effect of treatment schedule. J Pharmacol Exp Ther. 2001;296:1035-42.

126. Lu Z, Tsai M, Lu D, Wang J, Wientjes MG, Au JL. Tumor-penetrating microparticles for intraperitoneal therapy of ovarian cancer. J Pharmacol Exp Ther. 2008;327:673-82.

127. Kuhn SJ, Hallahan DE, Giorgio TD. Characterization of superparamagnetic nanoparticle interactions with extracellular matrix in an in vitro system. Ann Biomed Eng. 2006:34:51-58.

128. Olive KP, Jacobetz MA, Davidson CJ, Gopinathan A, Mclntyre D, Honess D, et al. Inhibition of Hedgehog signaling enhances delivery of chemotherapy in a mouse model of pancreatic cancer. Science. 2009;324:1457-61.

129. Phan-Lai V, Florczyk SJ, Kievit FM, Wang K, Gad E, Disis ML, et al. Threedimensional scaffolds to evaluate tumor associated fibroblast-mediated suppression of breast tumor specific T cells. Biomacromolecules. 2013;14:1330-7.

130. Brennen WN, Rosen DM, Wang H, Isaacs JT, Denmeade SR. Targeting carcinomaassociated fibroblasts within the tumor stroma with a fibroblast activation protein-activated prodrug. J Natl Cancer Inst. 2012;104:1320-34.

131. Wei L, Ye H, Li G, Lu Y, Zhou Q, Zheng S, et al. Cancer-associated fibroblasts promote progression and gemcitabine resistance via the SDF-1/SATB-1 pathway in pancreatic cancer. Cell Death Dis. 2018;9:1065.

132. Hou CM, Qu XM, Zhang J, Ding TT, Han W, Ji GC, et al. Fibroblast activation proteins-alpha suppress tumor immunity by regulating $T$ cells and tumorassociated macrophages. Exp Mol Pathol. 2018;104:29-37.

133. Miao L, Newby JM, Lin CM, Zhang L, Xu F, Kim WY, et al. The Binding site barrie elicited by tumor-associated fibroblasts interferes disposition of nanoparticles in stroma-vessel type tumors. ACS Nano. 2016;10:9243-58
134. Hu K, Miao L, Goodwin TJ, Li J, Liu Q, Huang L. Quercetin remodels the tumor microenvironment to improve the permeation, retention, and antitumor effects of nanoparticles. ACS Nano. 2017;11:4916-25.

135. Miao L, Liu Q, Lin CM, Luo C, Wang Y, Liu L, et al. Targeting tumor-associated fibroblasts for therapeutic delivery in desmoplastic tumors. Cancer Res. 2017;77: 719-31.

136. Gialeli $C$, Theocharis AD, Karamanos NK. Roles of matrix metalloproteinases in cancer progression and their pharmacological targeting. FEBS J. 2011;278:16-27.

137. Liu J, Chen Q, Feng L, Liu Z. Nanomedicine for tumor microenvironment modulation and cancer treatment enhancement. Nano Today. 2018;21:55-73.

138. Deng G, Zhou F, Wu Z, Zhang F, Niu K, Kang Y, et al. Inhibition of cancer cell migration with CuS@mSiO2-PEG nanoparticles by repressing MMP-2/MMP-9 expression. Int J Nanomed. 2018;13:103-16.

139. Meng $H$, Xing G, Blanco E, Song $Y$, Zhao L, Sun B, et al. Gadolinium metallofullerenol nanoparticles inhibit cancer metastasis through matrix metalloproteinase inhibition: imprisoning instead of poisoning cancer cells. Nanomedicine. 2012;8:136-46.

140. Levental KR, Yu H, Kass L, Lakins JN, Egeblad M, Erler JT, et al. Matrix crosslinking forces tumor progression by enhancing integrin signaling. Cell. 2009;139:891-906.

141. Siddikuzzaman Grace VM, Guruvayoorappan C. Lysyl oxidase: a potential target for cancer therapy. Inflammopharmacology. 2011;19:117-29.

142. Kanapathipillai M, Mammoto A, Mammoto T, Kang JH, Jiang E, Ghosh K, et al. Inhibition of mammary tumor growth using lysyl oxidase-targeting nanoparticles to modify extracellular matrix. Nano Lett. 2012;12:3213-7.

143. Zhang YX, Zhao YY, Shen J, Sun X, Liu Y, Liu H, et al. Nanoenabled modulation of acidic tumor microenvironment reverses anergy of infiltrating $T$ cells and potentiates anti-PD-1 therapy. Nano Lett. 2019;19:2774-83.

144. Bilir C, Sarisozen C. Indoleamine 2,3-dioxygenase (IDO): Only an enzyme or a checkpoint controller? J Oncol Sci. 2017;3:52-56.

145. Cheng K, Ding Y, Zhao Y, Ye S, Zhao X, Zhang Y, et al. Sequentially responsive therapeutic peptide assembling nanoparticles for dual-targeted cancer immunotherapy. Nano Lett. 2018;18:3250-8.

146. Lu J, Liu X, Liao YP, Wang X, Ahmed A, Jiang W, et al. Breast cancer chemoimmunotherapy through liposomal delivery of an immunogenic cell death stimulus plus interference in the IDO-1 pathway. ACS Nano. 2018;12:11041-61.

147. Lee S, Margolin K. Cytokines in cancer immunotherapy. Cancers. 2011;3: 3856-93.

148. Christian DA, Hunter CA. Particle-mediated delivery of cytokines for immunotherapy. Immunotherapy. 2012;4:425-41.

149. Konrad MW, Hemstreet G, Hersh EM, Mansell PW, Mertelsmann R, Kolitz JE, et al. Pharmacokinetics of recombinant interleukin 2 in humans. Cancer Res. 1990;50: 2009-17.

150. Anderson PM, Hasz D, Dickrell L, Sencer S. Interleukin-2 in liposomes: increased intravenous potency and less pulmonary toxicity in the rat. Drug Dev Res. 1992;27:15-31.

151. Hill HC, Conway TF Jr, Sabel MS, Jong YS, Mathiowitz E, Bankert RB, et al. Cancer immunotherapy with interleukin 12 and granulocyte-macrophage colony-stimulating factor-encapsulated microspheres: coinduction of innate and adaptive antitumor immunity and cure of disseminated disease. Cancer Res. 2002;62 7254-63.

152. Zídek Z, Anzenbacher P, Kmonícková E. Current status and challenges of cytokine pharmacology. Br J Pharmacol. 2009;157:342-61.

153. Milling L, Zhang Y, Irvine DJ. Delivering safer immunotherapies for cancer. Adv Drug Deliv Rev. 2017;114:79-101.

154. Liu X, Gao X, Zheng S, Wang B, Li Y, Zhao $C$, et al. Modified nanoparticle mediated IL-12 immunogene therapy for colon cancer. Nanomedicine. 2017;13: 1993-2004.

155. Huang KW, Hsu FF, Qiu JT, Chern GJ, Lee YA, Chang CC, et al. Highly efficient and tumor-selective nanoparticles for dual-targeted immunogene therapy against cancer. Sci Adv. 2020;6:eaax5032.

156. Baxevanis CN, Perez SA. Cancer vaccines: limited success but the research should remain viable. Expert Rev Vaccines. 2016;15:677-80.

157. Kelderman S, Schumacher TNM, Haanen JBAG. Acquired and intrinsic resistance in cancer immunotherapy. Mol Oncol. 2014;8:1132-9.

158. Conlon KC, Miljkovic MD, Waldmann TA. Cytokines in the treatment of cancer. J Interferon Cytokine Res. 2019;39:6-21.

159. Bonifant $\mathrm{CL}$, Jackson HJ, Brentjens RJ, Curran KJ. Toxicity and management in CAR T-cell therapy. Mol Ther Oncolytics. 2016;3:16011.

160. Marin-Acevedo JA, Chirila RM, Dronca RS. Immune checkpoint inhibitor toxicities. Mayo Clin Proc. 2019;94:1321-9.

161. Yin Z, Bai L, Li W, Zeng T, Tian H, Cui J. Targeting T cell metabolism in the tumor microenvironment: an anti-cancer therapeutic strategy. J Exp Clin Cancer Res. 2019;38:403.

162. Hammami A, Allard D, Allard B, Stagg J. Targeting the adenosine pathway for cancer immunotherapy. Semin Immunol. 2019;42:101304. 
163. Petitprez F, de Reyniès A, Keung EZ, Chen TWW, Sun CM, Calderaro J, et al. B cells are associated with survival and immunotherapy response in sarcoma. Nature. 2020;577:556-60.

164. Cabrita R, Lauss M, Sanna A, Donia M, Skaarup Larsen M, Mitra S, et al. Tertiary lymphoid structures improve immunotherapy and survival in melanoma. Nature. 2020:577:561-5.

165. Helmink BA, Reddy SM, Gao J, Zhang S, Basar R, Thakur R, et al. B cells and tertiary lymphoid structures promote immunotherapy response. Nature. 2020;577:549-55.

166. Johansson-Percival A, He B, Li ZJ, Kjellén A, Russell K, Li J, et al. De novo induction of intratumoral lymphoid structures and vessel normalization enhances immunotherapy in resistant tumors. Nat Immunol. 2017; 18:1207-17.

167. Phuengkham H, Ren L, Shin IW, Lim YT. Nanoengineered immune niches for reprogramming the immunosuppressive tumor microenvironment and enhancing cancer immunotherapy. Adv Mater. 2019;31:1803322.

168. Golden E, Formenti S. Is tumor (R)ejection by the immune system the " 5 th R" of radiobiology? Oncolmmunology. 2014;3:e28133.

169. Luo M, Liu Z, Zhang X, Han C, Samandi LZ, Dong C, et al. Synergistic STING activation by PC7A nanovaccine and ionizing radiation improves cancer immunotherapy. J Control Release. 2019;300:154-60.

170. Min Y, Roche KC, Tian S, Eblan MJ, McKinnon KP, Caster JM, et al. Antigencapturing nanoparticles improve the abscopal effect and cancer immunotherapy. Nat Nanotechnol. 2017;12:877-82.

171. Kepp O, Marabelle A, Zitvogel L, Kroemer G. Oncolysis without virusesinducing systemic anticancer immune responses with local therapies. Nat Rev Clin Oncol. 2020;17:49-64.

172. Zhang R, Zhu Z, Lv H, Li F, Sun S, Li J, et al. Immune checkpoint blockade mediated by a small-molecule nanoinhibitor targeting the PD-1/PD-L1 pathway synergizes with photodynamic therapy to elicit antitumor immunity and antimetastatic effects on breast cancer. Small. 2019;15:e1903881.

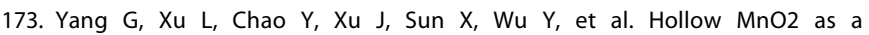
tumor-microenvironment-responsive biodegradable nano-platform for combination therapy favoring antitumor immune responses. Nat Commun. 2017;8:902.

174. Yan S, Zeng X, Tang YA, Liu BF, Wang Y, Liu X. Activating antitumor immunity and antimetastatic effect through polydopamine-encapsulated core-shell upconversion nanoparticles. Adv Mater. 2019;31:e1905825.

175. Liu Y, Pan Y, Cao W, Xia F, Liu B, Niu J, et al. A tumor microenvironment responsive biodegradable $\mathrm{CaCO}(3) / \mathrm{MnO}(2)$ - based nanoplatform for the enhanced photodynamic therapy and improved PD-L1 immunotherapy. Theranostics. 2019;9:6867-84.

176. Xu C, Nam J, Hong H, Xu Y, Moon JJ. Positron emission tomography-guided photodynamic therapy with biodegradable mesoporous silica nanoparticles for personalized cancer immunotherapy. ACS Nano. 2019;13:12148-61.

177. Ni K, Luo T, Lan G, Culbert A, Song $Y, W u ~ T$, et al. Nanoscale metal-organic frameworks mediate photodynamic therapy and deliver $\mathrm{CpG}$ oligodeoxynucleotides to enhance antigen presentation and cancer immunotherapy. Angew Chem Int Ed. 2019;59:11429.

178. Bañobre-López M, Teijeiro A, Rivas J. Magnetic nanoparticle-based hyperthermia for cancer treatment. Rep. Pr Oncol Radiother. 2013;18:397-400.

179. Wen Y, Chen X, Zhu X, Gong Y, Yuan G, Qin X, et al. Photothermal-chemotherapy integrated nanoparticles with tumor microenvironment response enhanced the induction of immunogenic cell death for colorectal cancer efficient treatment. ACS Appl Mater Interfaces. 2019;11:43393-408.

180. Huang L, Li Y, Du Y, Zhang Y, Wang X, Ding Y, et al. Mild photothermal therapy potentiates anti-PD-L1 treatment for immunologically cold tumors via an all-inone and all-in-control strategy. Nat Commun. 2019;10:4871.

181. Ma Y, Zhang Y, Li X, Zhao Y, Li M, Jiang W, et al. Near-infrared II phototherapy induces deep tissue immunogenic cell death and potentiates cancer immunotherapy. ACS Nano. 2019;13:11967-80.

182. Wang J, Meng J, Ran W, Lee RJ, Teng L, Zhang P, et al. Hepatocellular carcinoma growth retardation and PD-1 blockade therapy potentiation with synthetic high-density lipoprotein. Nano Lett. 2019;19:5266-76.

183. Zhang N, Song J, Liu Y, Liu M, Zhang L, Sheng D, et al. Photothermal therapy mediated by phase-transformation nanoparticles facilitates delivery of anti-PD1 antibody and synergizes with antitumor immunotherapy for melanoma. J Control Release. 2019;306:15-28.

184. Xu L, Zhang W, Park HB, Kwak M, Oh J, Lee PCW, et al. Indocyanine green and poly I:C containing thermo-responsive liposomes used in immunephotothermal therapy prevent cancer growth and metastasis. J Immunother Cancer. 2019;7:220.

185. Guo $Y$, Ran $Y$, Wang $Z$, Cheng J, Cao $Y$, Yang $C$, et al. Magnetic-responsive and targeted cancer nanotheranostics by PA/MR bimodal imaging-guided photothermally triggered immunotherapy. Biomaterials. 2019;219:119370.
186. Dong X, Liang J, Yang A, Qian Z, Kong D, Lv F. Fluorescence imaging guided CpG nanoparticles-loaded IR820-hydrogel for synergistic photothermal immunotherapy. Biomaterials. 2019;209:111-25.

187. Ye X, Liang X, Chen Q, Miao Q, Chen X, Zhang X, et al. Surgical tumor-derived personalized photothermal vaccine formulation for cancer immunotherapy. ACS Nano. 2019;13:2956-68.

188. Chen Q, Hu Q, Dukhovlinova E, Chen G, Ahn S, Wang C, et al. Photothermal therapy promotes tumor infiltration and antitumor activity of CAR T cells. Adv Mater. 2019;31:1900192.

189. Probst U, Fuhrmann I, Beyer L, Wiggermann P. Electrochemotherapy as a new modality in interventional oncology: a review. Technol Cancer Res Treat. 2018;17:1533033818785329.

190. Mun EJ, Babiker HM, Weinberg U, Kirson ED, Von Hoff DD. Tumor-treating fields: a fourth modality in cancer treatment. Clin Cancer Res. 2018;24:266-75.

191. Mozzillo N, Simeone E, Benedetto L, Curvietto M, Giannarelli D, Gentilcore G, et al. Assessing a novel immuno-oncology-based combination therapy: Ipilimumab plus electrochemotherapy. Oncoimmunology. 2015;4:e1008842.

192. Heppt MV, Eigentler TK, Kähler KC, Herbst RA, Göppner D, Gambichler T, et al. Immune checkpoint blockade with concurrent electrochemotherapy in advanced melanoma: a retrospective multicenter analysis. Cancer Immunol Immunother. 2016;65:951-9.

193. Giladi M, Voloshin T, Shteingauz A, Munster M, Blat R, Porat $Y$, et al. The antitumor activity of alternating electric fields (TTFields) in combination with immune checkpoint inhibitors. J Clin Oncol. 2016;34:e14570.

194. Marelli G, Howells A, Lemoine NR, Wang Y. Oncolytic viral therapy and the immune system: a double-edged sword against cancer. Front Immunol. 2018;9:866.

195. Maroun J, Muñoz-Alía M, Ammayappan A, Schulze A, Peng KW, Russell S. Designing and building oncolytic viruses. Future Virol. 2017;12:193-213.

196. Lichty BD, Breitbach CJ, Stojdl DF, Bell JC. Going viral with cancer immunotherapy. Nat Rev Cancer. 2014;14:559-67.

197. Vijayakumar G, Palese P, Goff PH. Oncolytic Newcastle disease virus expressing a checkpoint inhibitor as a radioenhancing agent for murine melanoma. EBioMedicine. 2019;49:96-105.

198. Du T, Shi G, Li YM, Zhang JF, Tian HW, Wei YQ, et al. Tumor-specific oncolytic adenoviruses expressing granulocyte macrophage colony-stimulating factor or anti-CTLA4 antibody for the treatment of cancers. Cancer Gene Ther. 2014; 21:340-8.

199. Havunen R, Siurala M, Sorsa S, Grönberg-Vähä-Koskela S, Behr M, Tähtinen S, et al. Oncolytic adenoviruses armed with tumor necrosis factor alpha and interleukin-2 enable successful adoptive cell therapy. Mol Ther Oncolytics. 2017:4:77-86

200. Haque $S$, Morris JC. Transforming growth factor- $\beta$ : A therapeutic target for cancer. Hum Vaccin Immunother. 2017;13:1741-50.

201. Lemdani K, Seguin J, Lesieur C, Al Sabbagh C, Doan BT, Richard C, et al. Mucoadhesive thermosensitive hydrogel for the intra-tumoral delivery of immunomodulatory agents, in vivo evidence of adhesion by means of noninvasive imaging techniques. Int J Pharm. 2019;567:118421.

202. Lemdani K, Mignet N, Boudy V, Seguin J, Oujagir E, Bawa O, et al. Local immunomodulation combined to radiofrequency ablation results in a complete cure of local and distant colorectal carcinoma. Oncolmmunology. 2019;8: 1550342.

203. Driessens G, Nuttin L, Gras A, Maetens J, Mievis S, Schoore M, et al. Development of a successful antitumor therapeutic model combining in vivo dendritic cell vaccination with tumor irradiation and intratumoral GM-CSF delivery. Cancer Immunol Immunother. 2011;60:273-81.

204. Hammerich L, Marron TU, Upadhyay R, Svensson-Arvelund J, Dhainaut $M$, Hussein $\mathrm{S}$, et al. Systemic clinical tumor regressions and potentiation of PD1 blockade with in situ vaccination. Nat Med. 2019;25:814-24.

205. Sánchez-Paulete AR, Teijeira Á, Quetglas Jl, Rodríguez-Ruiz ME, Sánchez-Arráez Á, Labiano $S$, et al. Intratumoral immunotherapy with XCL1 and sFlt3L encoded in recombinant semliki forest virus-derived vectors fosters dendritic cell-mediated Tcell cross-priming. Cancer Res. 2018;78:6643-54.

206. Nuhn L, De Koker S, Van Lint S, Zhong Z, Catani JP, Combes F, et al. Nanoparticle-conjugate TLR7/8 agonist localized immunotherapy provokes safe antitumoral responses. Adv Mater. 2018;30:e1803397.

207. Yang YSS, Moynihan KD, Bekdemir A, Dichwalkar TM, Noh MM, Watson N, et al. Targeting small molecule drugs to T cells with antibody-directed cell-penetrating gold nanoparticles. Biomater Sci. 2018;7:113-24.

208. Lan Y, Zhang D, Xu C, Hance KW, Marelli B, Qi J, et al. Enhanced preclinical antitumor activity of M7824, a bifunctional fusion protein simultaneously targeting PD-L1 and TGF- $\beta$. Sci Transl Med. 2018;10:eaan5488.

209. Lang T, Liu Y, Zheng Z, Ran W, Zhai Y, Yin Q, et al. Cocktail strategy based on spatio-temporally controlled nano device improves therapy of breast cancer. Adv Mater. 2019;31:e1806202. 
210. Compte M, Harwood SL, Muñoz IG, Navarro R, Zonca M, Perez-Chacon G, et al. A tumor-targeted trimeric 4-1BB-agonistic antibody induces potent anti-tumor immunity without systemic toxicity. Nat Commun. 2018;9:4809.

211. Hassan HAFM, Smyth L, Wang JTW, Costa PM, Ratnasothy K, Diebold SS, et al. Dual stimulation of antigen presenting cells using carbon nanotube-based vaccine delivery system for cancer immunotherapy. Biomaterials. 2016;104:310-22.

212. Bowen WS, Svrivastava AK, Batra L, Barsoumian H, Shirwan H. Current challenges for cancer vaccine adjuvant development. Expert Rev Vaccines. 2018;17:207-15.

213. Vermaelen K. Vaccine strategies to improve anti-cancer cellular immune responses. Front Immunol. 2019;10:8.

214. Kadiyala P, Li D, Nuñez FM, Altshuler D, Doherty R, Kuai R, et al. High-density lipoprotein-mimicking nanodiscs for chemo-immunotherapy against glioblastoma multiforme. ACS Nano. 2019;13:1365-84.

215. An M, Yu C, Xi J, Reyes J, Mao G, Wei WZ, et al. Induction of necrotic cell death and activation of STING in the tumor microenvironment via cationic silica nanoparticles leading to enhanced antitumor immunity. Nanoscale. 2018;10:9311-9.
Open Access This article is licensed under a Creative Commons Attribution 4.0 International License, which permits use, sharing, adaptation, distribution and reproduction in any medium or format, as long as you give appropriate credit to the original author(s) and the source, provide a link to the Creative Commons license, and indicate if changes were made. The images or other third party material in this article are included in the article's Creative Commons license, unless indicated otherwise in a credit line to the material. If material is not included in the article's Creative Commons license and your intended use is not permitted by statutory regulation or exceeds the permitted use, you will need to obtain permission directly from the copyright holder. To view a copy of this license, visit http://creativecommons. org/licenses/by/4.0/.

(c) The Author(s) 2020 